\title{
Dual-Band RF Wireless Power Transfer System with a Shared-Aperture Dual-Band Tx Array Antenna
}

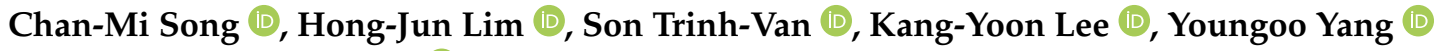 \\ and Keum-Cheol Hwang *(D)
}

Department of Electrical and Computer Engineering, Sungkyunkwan University, Suwon 440-746, Korea; 94chanmi@gmail.com (C.-M.S.); zpeac@naver.com (H.-J.L.); jsonbkhn@gmail.com (S.T.-V.); klee@skku.edu (K.-Y.L.); yang09@skku.edu (Y.Y.)

* Correspondence: khwang@skku.edu; Tel.: +82-31-290-7978

Citation: Song, C.M.; Lim, H.J.; Trinh-Van, S.; Lee, K.-Y.; Yang, Y.; Hwang, K.C. Dual-Band RF Wireless Power Transfer System with a Shared-Aperture Dual-Band Tx Array Antenna. Energies 2021, 14, 3803. https://doi.org/10.3390/en14133803

Academic Editor: William Holderbaum

Received: 25 May 2021

Accepted: 21 June 2021

Published: 24 June 2021

Publisher's Note: MDPI stays neutral with regard to jurisdictional claims in published maps and institutional affiliations.

Copyright: (c) 2021 by the authors. Licensee MDPI, Basel, Switzerland. This article is an open access article distributed under the terms and conditions of the Creative Commons Attribution (CC BY) license (https:/ / creativecommons.org/licenses/by/ $4.0 /)$.
Abstract: In this paper, a dual-band RF wireless power transfer (WPT) system with a shared-aperture dual-band Tx array antenna for 2.4 and $5.8 \mathrm{GHz}$ is proposed. The final configuration of the Tx array, which is made up of $2.4 \mathrm{GHz}$ right-handed circular polarization (RHCP) patches and $5.8 \mathrm{GHz} \mathrm{RHCP}$ patches, is derived from the optimization of 2.4 and $5.8 \mathrm{GHz}$ thinned arrays, ultimately to achieve high transmission efficiency for various WPT scenarios. The dual-band RF WPT Tx system including the Tx array antenna and a Tx module is implemented, and Rx antennas with a $2.4 \mathrm{GHz}$ patch, a $5.8 \mathrm{GHz}$ patch, and a dual-band $(2.4$ and $5.8 \mathrm{GHz})$ patch are developed. To validate the proposed dual-band RF WPT system, WPT experiments using a single band and dual bands were conducted. When transmitting RF wireless power on a single frequency (either $2.482 \mathrm{GHz}$ or $5.73 \mathrm{GHz}$ ), the received power according to the distance between the Tx and $\mathrm{Rx}$ and the position of the Rx was measured. When the distance was varied from $1 \mathrm{~m}$ to $3.9 \mathrm{~m}$ and the transmitted power was $40 \mathrm{dBm}$, the received power value at $2.482 \mathrm{GHz}$ and $5.73 \mathrm{GHz}$ were measured and found to be $24.75-13.5 \mathrm{dBm}$ (WPT efficiency $=2.985-0.224 \%$ ) and 19.25-6.8 dBm (WPT efficiency $=0.841-0.050 \%$ ), respectively. The measured results were in good agreement with the calculated results, and it is revealed that the transmission efficiency when wireless power is transmitted via beam-focusing increases more than that with conventional beam-forming. Furthermore, the dual-band WPT experiment proves that $2.482 \mathrm{GHz}$ beam and $5.73 \mathrm{GHz}$ beams can be formed individually and that their wireless power can be transmitted to a dual-band Rx or two different Rx.

Keywords: wireless power transfer; microwave power transfer; array antenna; thinned array; dualband; shared-aperture antenna; beam-focusing; beam-forming

\section{Introduction}

Recently, with the advancement of Internet of Things (IoT) technology and the expansion of the corresponding market, the issue of supplying energy to wireless sensors for the IoT has become a hot topic. Most IoT devices must be supplied constantly but many consume relatively less power, making them suitable for charging by wireless power transfer (WPT) through radio frequency (RF) technology. Various studies related to this have been conducted [1-5].

Most RF WPT systems use a single-band frequency within the industrial scientific medical (ISM) band, such as $915 \mathrm{MHz}, 2.4 \mathrm{GHz}$, or 5.8 GHz [2,6-9]. These ISM bands are highly utilized and are already occupied by various applications and devices [10,11]. Therefore, a RF WPT system using only a single frequency on the ISM band is not only exposed to a complex frequency environment but can also cause disruptions to nearby communication devices. If a dual-band WPT system with a dual-band power transmitter (Tx) system is implemented, as shown in Figure 1, the operating frequency (in this case, either $f_{1}$ or $f_{2}$ ) of the WPT system can be selected appropriately according to the given 
frequency environment and wireless power can be transmitted to a receiver (Rx). Examples include (a) transmitting $f_{1}$ wireless power to an $\operatorname{Rx}$ for $f_{1}$, (b) transmitting $f_{2}$ wireless power to an $\operatorname{Rx}$ for $f_{2}$, (c) transmitting dual-band wireless power of $f_{1}$ and $f_{2}$ to an Rx for the dual band, and (d) transmitting $f_{1}$ wireless power and $f_{2}$ wireless power to an $\mathrm{Rx}$ for $f_{1}$ and to another Rx for $f_{2}$, respectively. This facilitates diversity of the operating frequency and therefore allows flexible operation of the WPT system in various situations and scenarios. However, most research on dual-band WPT systems focuses on inductive coupling and magnetic resonant coupling WPT methods [12-15]. These WPT systems have a disadvantage in that the power transmission distance is short. On the other hand, for dual-band RF WPT, a printed dual-band antenna of 2.5 and $4.5 \mathrm{GHz}$ was proposed [16] and a dual-band antenna operating at 2.45 and $5.8 \mathrm{GHz}$ was designed based on a split-ring resonator and fractal geometry [17], respectively. Another study presents the design of a dual-band power amplifier operating at 2.4 and $5.8 \mathrm{GHz}$ based on the concept of composite right/left-handed (CRLH) unit cells and substrate-integrated waveguide (SIW) technology [18]. A dual-band rectenna optimized to convert far-field RF energy to DC voltage at very low received power levels at $915 \mathrm{MHz}$ and $2.44 \mathrm{GHz}$ was also developed [19]. Like this, most works related to dual-band RF WPT have concentrated on dual-band components such as antennas, amplifiers, and circuits, but studies of the design and testing of dual-band RF WPT systems have rarely been carried out. Recently, a dual-band RF WPT system based on a frequencyreconfigurable antenna array (covering the S-band and C-band) was proposed [20], but the frequency reconfigurable antenna required a change of the connection method between the main patch and smaller patches in order to adjust the operating frequency. Furthermore, in this case, the power transmission distance was relatively short, from $20 \mathrm{~mm}$ to $80 \mathrm{~mm}$, and beam-forming was not considered.

In this paper, a dual-band WPT system with a shared-aperture dual-band employing $2.4 \mathrm{GHz}$ radiating elements and $5.8 \mathrm{GHz}$ radiating elements in a single aperture is proposed. In Section 2, a dual-band aperture-sharing array as a Tx antenna is optimally designed to achieve high transmission efficiency in various WPT scenarios. Based on this optimized Tx array antenna, the dual-band RF Tx system is implemented. Rx antennas are also designed. In Section 3, the measured results from WPT experiments according to various WPT scenarios, as depicted in Figure 1, are detailed. Finally, Section 4 presents the conclusions of this study.

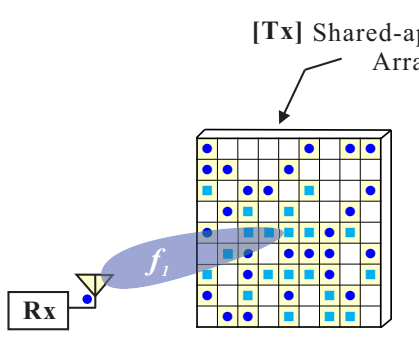

(a)

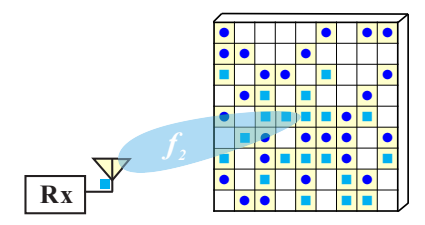

(b)

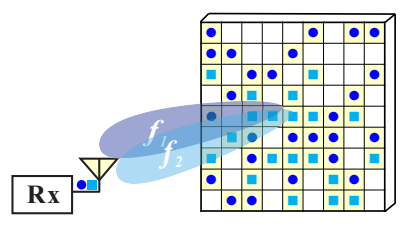

(c)

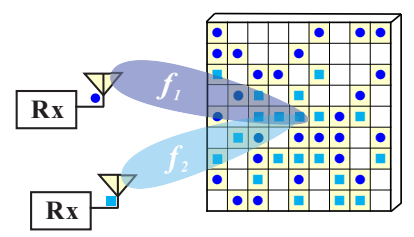

(d)

Figure 1. Wireless power transfer (WPT) scenarios according to use of the frequency and the transmission of the beam: (a) transmitting $f_{1}$ wireless power to an $\mathrm{Rx}$ for $f_{1},(\mathbf{b})$ transmitting $f_{2}$ wireless power to an $\mathrm{Rx}$ for $f_{2}$, (c) transmitting dual-band wireless power of $f_{1}$ and $f_{2}$ to an $\mathrm{Rx}$ for the dual band, and (d) transmitting $f_{1}$ wireless power and $f_{2}$ wireless power to an $\mathrm{Rx}$ for $f_{1}$ and to another $\mathrm{Rx}$ for $f_{2}$, respectively.

\section{Implementation of a Dual-Band RF Wireless Power Transfer (WPT) System}

In this paper, in order to avoid interference with other communications operating on the 2.4 and $5.8 \mathrm{GHz}$ bands, $2.482 \mathrm{GHz}$ (which is a frequency in the upper guard-band of the $2.4 \mathrm{GHz}$ band) and $5.73 \mathrm{GHz}$ (which is a frequency in the lower guard-band of the $5.8 \mathrm{GHz}$ band), are determined as operating frequencies for the proposed dual-band WPT system. Additionally, radiating elements that generate RHCP (right-handed circular polarization) 
are applied as array elements because using circular polarization can minimize polarization mismatch losses, ensuring polarization diversity in WPT system [21-23].

\subsection{Design of a Shared-Aperture Dual-Band Tx Array Antenna}

To merge a $2.4 \mathrm{GHz}$ array and a $5.8 \mathrm{GHz}$ array into a dual-band RF Tx system, a shared-aperture dual-band array based on the configuration of a thinned array is proposed as a Tx antenna [24,25]. This shared-aperture dual-band array is composed of a $2.4 \mathrm{GHz}$ thinned array with $2.4 \mathrm{GHz}$ radiating elements and a $5.8 \mathrm{GHz}$ thinned array with $5.8 \mathrm{GHz}$ radiating elements. As these two different array antennas are employed in a single planar structure, an aperiodic array configuration such as thinned array is necessary $[26,27]$. The configuration of the thinned array is derived by optimization, and optimization of the array is usually performed to ensure that desired far-field characteristics (such as the gain, beam width and side-lobe) are achieved [28-30]. However, when optimizing a thinned array for WPT, the transmission efficiency should be considered above all. The transmission efficiency (in other words, the WPT efficiency) is defined as $P_{R} / P_{T}$ (here, $P_{R}$ is the total received power and $P_{T}$ is the total transmitted power) and achieving high WPT efficiency is the ultimate goal of WPT technology. Therefore, in this paper, optimization of the thinned array for WPT is conducted with the aim of improving the transmission efficiency considering various power transmission scenarios.

We assume a square aperture $50 \mathrm{~cm} \times 50 \mathrm{~cm}$ in size with a grid of $31.23 \mathrm{~mm}$ spacing (equal to $0.26 \lambda$ for $2.482 \mathrm{GHz}$ and $0.60 \lambda$ for $5.73 \mathrm{GHz}$ ), as shown in Figure 2. Here, $\lambda$ is the wavelength of the operating frequency. We are supposed to arrange 32 elements for $2.4 \mathrm{GHz}$ and 32 elements for $5.8 \mathrm{GHz}$ on this aperture, constructing 2.4 and $5.8 \mathrm{GHz}$ thinned arrays, respectively. Both the $2.4 \mathrm{GHz}$ and $5.8 \mathrm{GHz}$ thinned arrays are strategically determined by optimization. When the center of this Tx aperture in Figure 2 is considered to be the origin and the position of the $\mathrm{Rx}$ is $\left(x^{\prime}, y^{\prime}, z^{\prime}\right)$, optimization of the thinned array is carried out with the aim of maximizing the evaluation function following Equation (1). In other words, an optimized arrangement of 32 elements for each frequency is derived to achieve maximum transmission efficiency, taking into account 25 WPT scenarios of transmitting power to a Rx position at $x^{\prime}=0.5 n, y^{\prime}=0.5 n$, and $z^{\prime}=2$ (when $n=-2,-1$, 0,1 , and 2).

Evaluation Function $=\sum_{n} \frac{P_{R}}{P_{T}}\left\{\right.$ when transmitting power to $\operatorname{Rx}$ position $\left.\left(x^{\prime}, y^{\prime}, z^{\prime}\right) \mid x^{\prime}=0.5 n, y^{\prime}=0.5 n, z^{\prime}=2\right\}$

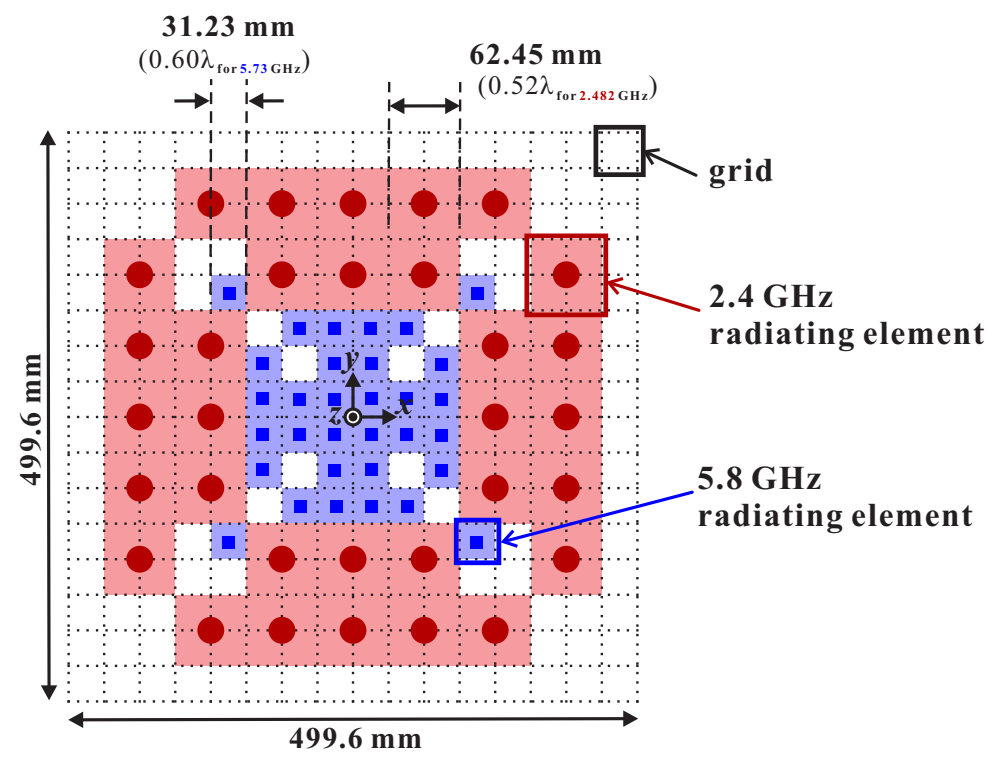

Figure 2. Arrangement of radiating elements in the optimized shared-aperture dual-band array. 
In this equation, $z^{\prime}=2$ denotes a distance of $2 \mathrm{~m}$ in the $+z$-direction between the Tx and $\mathrm{Rx}$ antennas; this distance is in not a far-field region but in the Fresnel region for the 2.4 and the 5.8 GHz arrays [31]. When $\beta_{m}$ and $\left(x_{m}, y_{m}, z_{m}\right)$ are defined as the excited phase and position of the $m$-th element of the Tx array, by feeding the phase calculated by Equation (2) into the $m$-th element, the beam can be formed in a desired direction (here, it is the direction to $\left.\operatorname{Rx}\left(\theta^{\prime}, \phi^{\prime}\right)\right)$ and power can be transmitted. This is known as beam-forming, and it is usually the method used for beam-steering. On the other hand, if the phase according to Equation (3) is applied as the excited phase of the $m$-th element, the transmitted beam is concentrated to a specific point (here, it is the location of $\left.\operatorname{Rx}\left(x^{\prime}, y^{\prime}, z^{\prime}\right)\right)$, known as beamfocusing. According to the literature [7,32-34], in the Fresnel region, using beam-focusing rather than beam-forming as a beam-steering method can improve the received power. Thus, we assume that the beam is sequentially formed to the $25 \mathrm{Rx}$ position in Equation (1) by applying the beam-focusing method.

$$
\begin{gathered}
\beta_{m}=x_{m} \sin \theta^{\prime} \cos \phi^{\prime}+y_{m} \sin \theta^{\prime} \sin \phi^{\prime} \\
\beta_{m}=\frac{2 \pi}{\lambda}\left(\sqrt{\left(x_{m}-x^{\prime}\right)^{2}+\left(y_{m}-y^{\prime}\right)^{2}+\left(z_{m}-z^{\prime}\right)^{2}}-\sqrt{\left(x^{\prime}\right)^{2}+\left(y^{\prime}\right)^{2}+\left(z^{\prime}\right)^{2}}\right)
\end{gathered}
$$

Equation (4) is the formula used to calculate the transmission efficiency for the RF WPT with the Tx array with M-elements based on numerical integration [35]. As it is more accurate than the Friis formula [31] in the Fresnel region, the evaluation function of Equation (1) is calculated using this Equation (4). In this paper, given that 32 radiating elements are used in both the 2.4 and $5.8 \mathrm{GHz}$ arrays, $M$ equals 32 here. $P_{t_{m}}$ is the excited power to the $m$-th Tx element, $G_{t_{m}}\left(\theta_{m}^{\prime}, \phi_{m}^{\prime}\right)$ is the realized gain of the co-polarization of the $m$-th Tx element in the direction of $\mathrm{Rx}$, and $G_{r}\left(\theta_{m}^{\prime},-\phi_{m}^{\prime}\right)$ is the realized gain of the co-polarization of the Rx element in the direction of the $m$-th Tx element. $R_{m}$ is expressed as $\sqrt{\left(x_{m}-x^{\prime}\right)^{2}+\left(y_{m}-y^{\prime}\right)^{2}+\left(z_{m}-z^{\prime}\right)^{2}}$, indicating the distance between the $m$-th $\mathrm{Tx}$ element and the Rx.

$$
\frac{P_{R}}{P_{T}}=\left(\frac{\lambda}{4 \pi}\right)^{2} \frac{\left|\sum_{m=1}^{M} \sqrt{P_{t_{m}} G_{t_{m}}\left(\theta_{m}^{\prime}, \phi_{m}^{\prime}\right) G_{r}\left(\theta_{m}^{\prime},-\phi_{m}^{\prime}\right)} \frac{e^{-j\left(k R_{m}-\beta_{m}\right)}}{R_{m}}\right|^{2}}{\sum_{m=1}^{M} P_{t_{m}}}
$$

During this optimization process, it is ensured that the elements of the two thinned arrays do not overlap and that each thinned array is made to have a quadrant symmetrical geometry around the origin. Optimization of the 2.4 and $5.8 \mathrm{GHz}$ thinned arrays was conducted sequentially in order to maximize Equation (1) based on Equation (4). As a result of the optimization, the final arrangement of each radiating element consisting of the 2.4 and $5.8 \mathrm{GHz}$ thinned arrays on the given single aperture is shown in Figure 2. Here, the $2.4 \mathrm{GHz}$ RHCP patch in Figure $3 \mathrm{a}$ is applied as the $2.4 \mathrm{GHz}$ radiating element, and the $5.8 \mathrm{GHz}$ RHCP patch in Figure $3 \mathrm{~b}$ is applied as the $5.8 \mathrm{GHz}$ radiating element. These corrugated patches are excited by a coaxial SMA connector and a $1.52 \mathrm{~mm}$ thick RF-35 substrate with $\varepsilon_{r}=3.5$ and $\tan \delta=0.0018$ is utilized as shown Figure 3c. Figure 4 illustrates the surface current distribution of the corrugated patch, which is observed from the $+z$-direction at the operating frequency. In this figure, $\bar{J}_{\text {total }}$ represents the vector sum of all major current vectors, and $T$ is the period of the operating frequency. When corrugation on both right and left sides of the square patch is applied and the feeding point is located with offset from the center, $\bar{J}_{\text {total }}$ rotates counterclockwise as the time $(t)$ increases and the RHCP is achieved. Accordingly, patch elements in the Figure $3 a, b$ can generate RHCP at $2.482 \mathrm{GHz}$ and at $5.73 \mathrm{GHz}$, respectively.

Figure 5 shows the final configuration and a photograph of the optimized sharedaperture dual-band array. As shown in Figure 3c, SMA connectors are connected to the patch elements. Figure 6 demonstrates the simulated and measured results of the reflection 
coefficients of several array elements shown in Figure 5. Figure $6 a, b$ describes the reflection coefficients of the $2.4 \mathrm{GHz}$ and $5.8 \mathrm{GHz}$ radiating elements, respectively. Regardless of where the radiating element is located in the final shared-aperture array, the reflection coefficients are less than $-10 \mathrm{~dB}$ at $2.482 \mathrm{GHz}$ and $5.73 \mathrm{GHz}$, and the corresponding measured results are in good agreement with the simulated results. Figure 7a shows that the RHCP-realized gains of $2.4 \mathrm{GHz}$ array antenna and $5.8 \mathrm{GHz}$ array antenna in the $+z$-direction are approximately $20 \mathrm{dBic}$ and $20.8 \mathrm{dBic}$, respectively. As shown in Figure $7 \mathrm{~b}$, the $3 \mathrm{~dB}$ axial ratio (AR) bandwidth of the $2.4 \mathrm{GHz}$ Tx array antenna in the +z-direction is $2.474-2.490 \mathrm{GHz}$ and the AR values at $2.482 \mathrm{GHz}$ is $1.16 \mathrm{~dB}$. For the $5.8 \mathrm{GHz}$ Tx array antenna, the $3 \mathrm{~dB}$ AR bandwidth in the $+z$-direction is $5.691-5.769 \mathrm{GHz}$ and the AR value is $0.758 \mathrm{~dB}$ at $5.73 \mathrm{GHz}$.

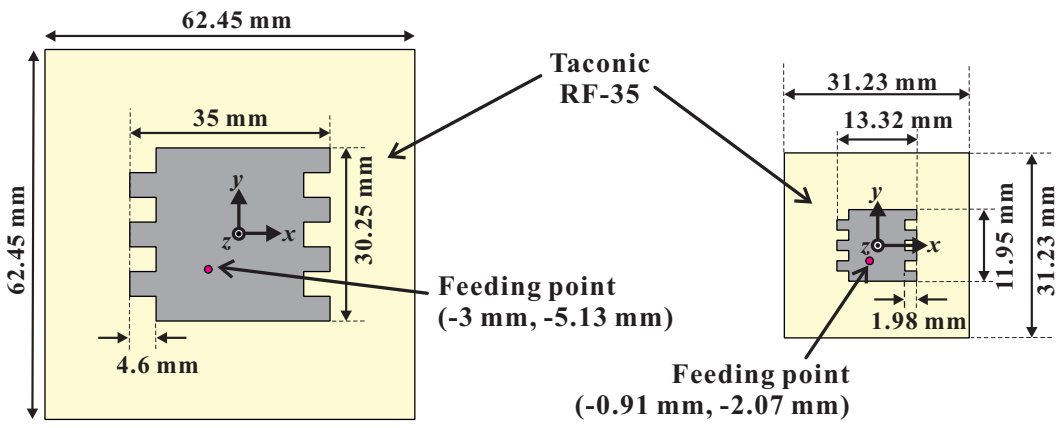

(a) (b)

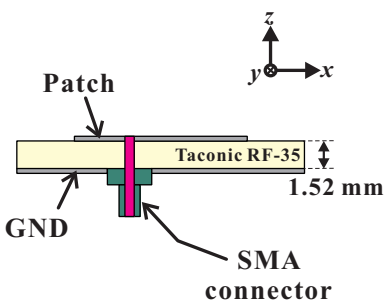

(c)

Figure 3. Radiating elements: (a) $2.4 \mathrm{GHz}$ RHCP (right-handed circular polarization) patch; (b) $5.8 \mathrm{GHz}$ RHCP patch; (c) sideview of the patches.
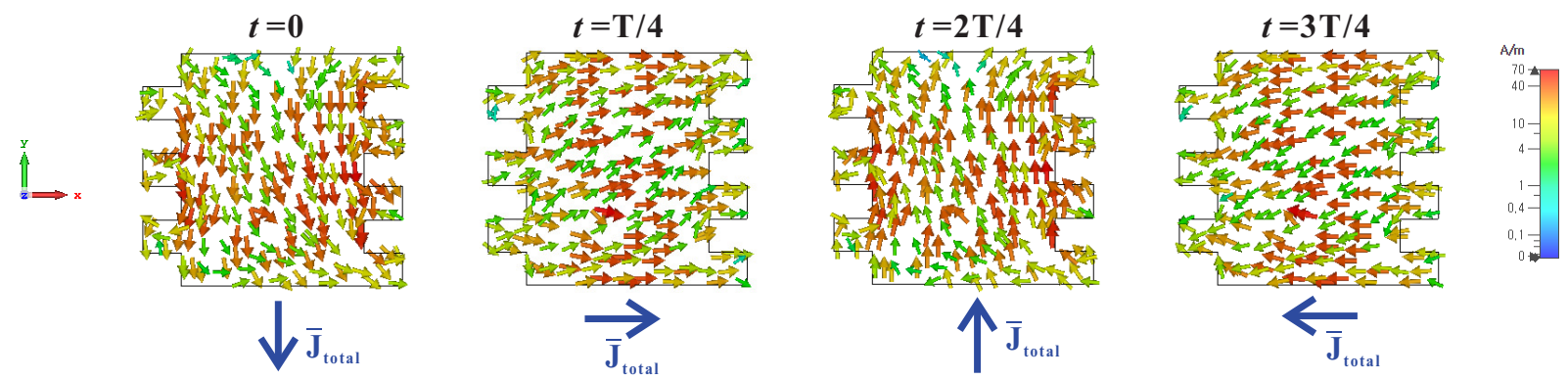

Figure 4. Simulated surface current distributions on the corrugated patch at the operating frequency.

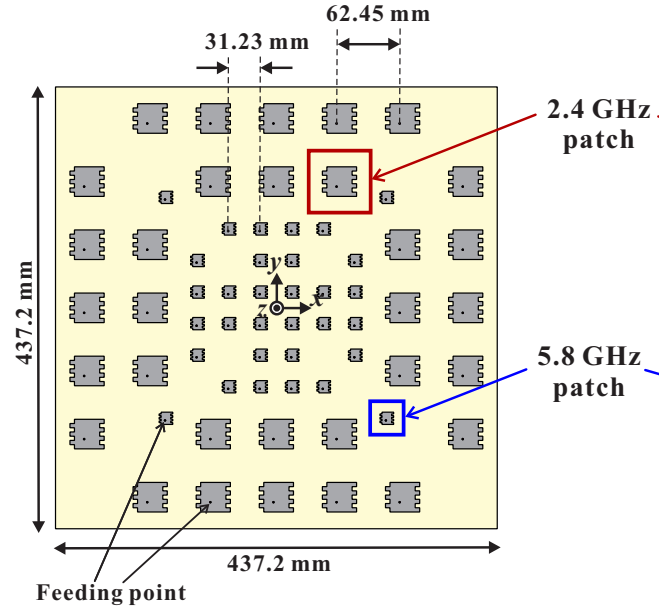

(a)

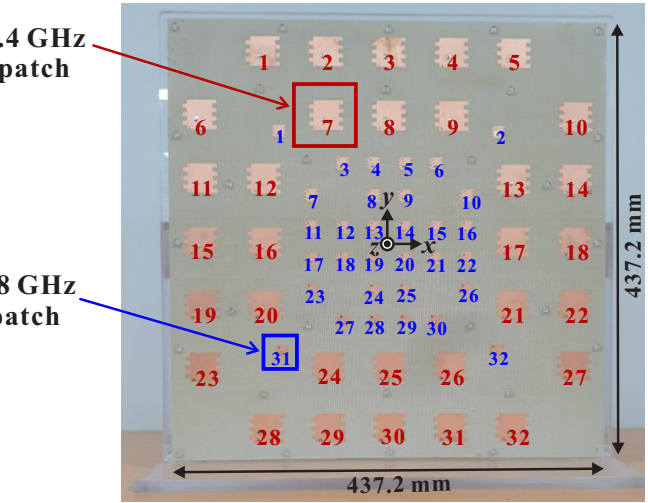

(b)

Figure 5. Optimized shared-aperture dual-band array: (a) configuration; (b) photograph. 


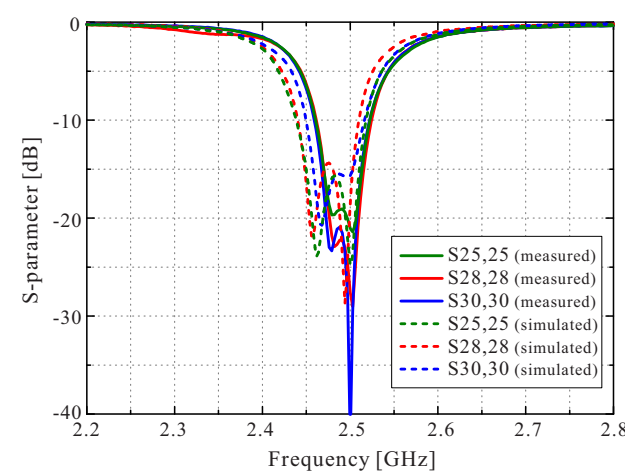

(a)

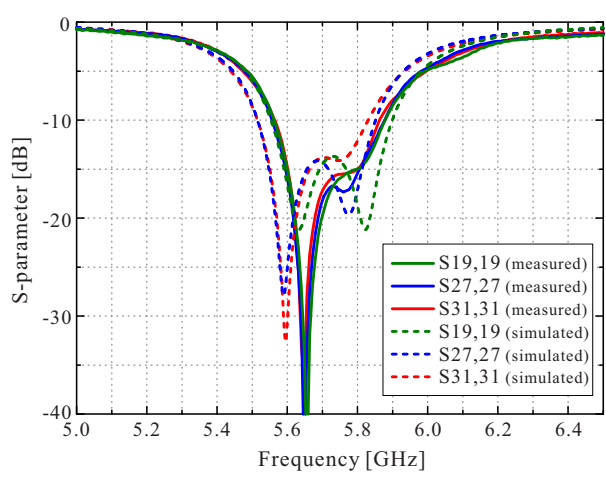

(b)

Figure 6. Reflection coefficients of the radiating elements in the proposed aperture-shared dual-band thinned array: (a) $2.4 \mathrm{GHz}$ band; (b) $5.8 \mathrm{GHz}$ band.

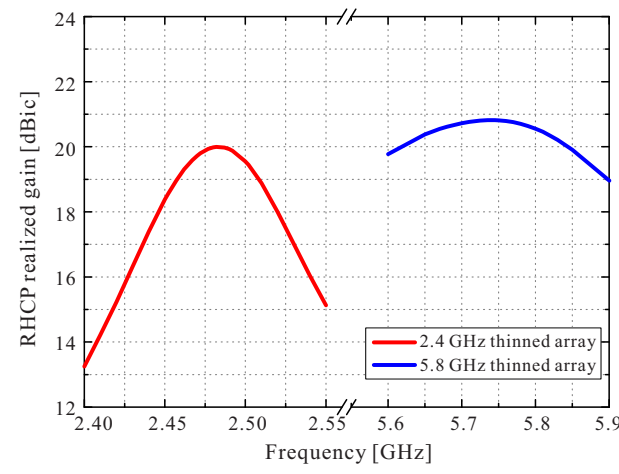

(a)

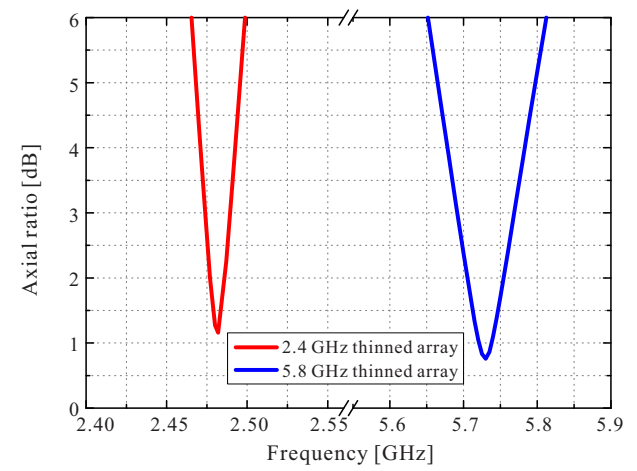

(b)

Figure 7. Simulated results of the proposed aperture-shared dual-band thinned array: (a) realized gain; (b) axial ratio.

Furthermore, adopting the shared-aperture array employing 2.4 and $5.8 \mathrm{GHz}$ radiating elements simultaneously in a single aperture has the effect of reducing the total area of the overall array antenna. Figure 8 a shows a $2.4 \mathrm{GHz}$ array with $2.4 \mathrm{GHz} 32$ elements and a gain of $20 \mathrm{dBic}$ at $2.482 \mathrm{GHz}$, having performance equivalent to the shared-aperture array. Figure $8 \mathrm{~b}$ is a $5.8 \mathrm{GHz}$ array with $5.8 \mathrm{GHz} 32$ elements and gain of $20.8 \mathrm{dBic}$ at $5.73 \mathrm{GHz}$, also showing $5.8 \mathrm{GHz}$ performance corresponding to the shared-aperture array. Table 1 presents the results of a comparison of these two single-band arrays, shown in Figure $8 a, b$, and the proposed shared-aperture array. If implementing a dual-band WPT system by stacking the two single-band arrays shown in Figures $8 \mathrm{a}, \mathrm{b}$, a total area of $57.3 \times 39 \mathrm{~cm}^{2}$ is required. In contrast, the area of the proposed shared-aperture array as depicted in Figure 5 is $43.7 \times 43.7 \mathrm{~cm}^{2}$, representing a size reduction of about $15 \%$ compared to when the two individual array antennas are stacked.

Table 1. Comparison according to the implementation method of the dual-band array system.

\begin{tabular}{ccccc}
\hline & $\begin{array}{c}\text { 2.4 GHz Array } \\
\text { (Figure 8a) }\end{array}$ & $\begin{array}{c}\text { 5.8 GHz Array } \\
\text { (Figure 8b) }\end{array}$ & $\begin{array}{c}\text { Proposed Dual-Band Array } \\
\text { (Figure 5) }\end{array}$ \\
\hline $\begin{array}{c}\text { Operating frequency } \\
\text { Radiating elements }\end{array}$ & $2.482 \mathrm{GHz}$ & $5.73 \mathrm{GHz}$ & $2.482 \mathrm{GHz}$ & $5.73 \mathrm{GHz}$ \\
Realized gain & 32 & 32 & 32 & 32 \\
Aperture area & $39 \times 39 \mathrm{dm}^{2}$ & $18.3 \times 18.3 \mathrm{~cm}^{2}$ & $20 \mathrm{dBic}$ & $20.8 \mathrm{dBic}$ \\
\hline
\end{tabular}




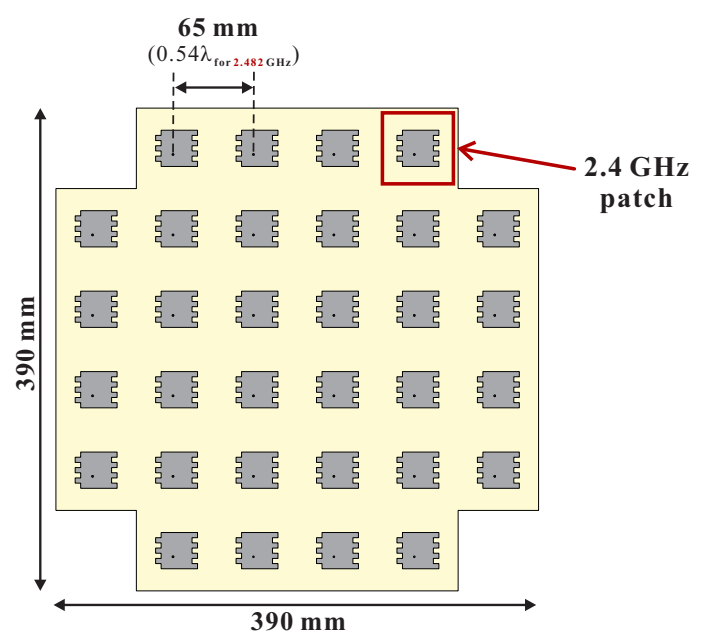

(a)

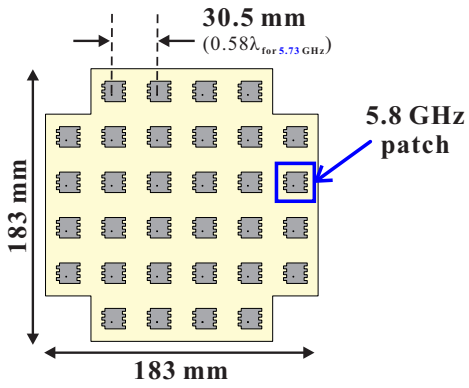

(b)

Figure 8. Single-band array antennas with performance equivalent to the proposed shared-aperture array: (a) $2.4 \mathrm{GHz}$ array; (b) $5.8 \mathrm{GHz}$ array.

\subsection{Implementation of the Dual-Band Tx System}

The dual-band Tx system including the proposed Tx array antenna and a Tx module is implemented as shown in Figure 9. The Tx array antenna is the optimized aperture-sharing dual-band array antenna shown in Figure 5. The Tx module, which is developed such that it can be divided into a $2.4 \mathrm{GHz}$ circuit part with $32 \mathrm{Tx}$ channels and a $5.8 \mathrm{GHz}$ circuit part with 32 Tx channels, controls the magnitude and phase of the signals fed to each radiating element in the Tx array antenna. A Tx channel is composed of a power divider, a 6-bit digital phase-shifter, a 6-bit digital attenuator, and amplifiers and is connected to a radiating element in the Tx array by means of an RF cable. In order to generate signals at $2.482 \mathrm{GHz}$ and $5.73 \mathrm{GHz}$, two signal generators are connected to the Tx module, with this module controlled by a GUI program on a control PC. When the RF signal of $2.482 \mathrm{GHz}$ is entered by the signal generator to the Tx module, the signal is divided into 32 channels through the 4-way and 8-way power dividers and amplified through the amplifiers in each Tx channel circuit. The phase and magnitude of the signal are varied by the phase-shifter and the attenuator, respectively. The output signal of $2.482 \mathrm{GHz}$ from the $2.4 \mathrm{GHz}$ Tx channel in the Tx module is delivered to the $2.4 \mathrm{GHz}$ patch-radiating element connected by a RF cable, and the exited patch antenna finally radiates the RF signal into the air. This process of feeding the $2.4 \mathrm{GHz}$ radiating elements is identical for the $5.8 \mathrm{GHz}$ radiating elements.

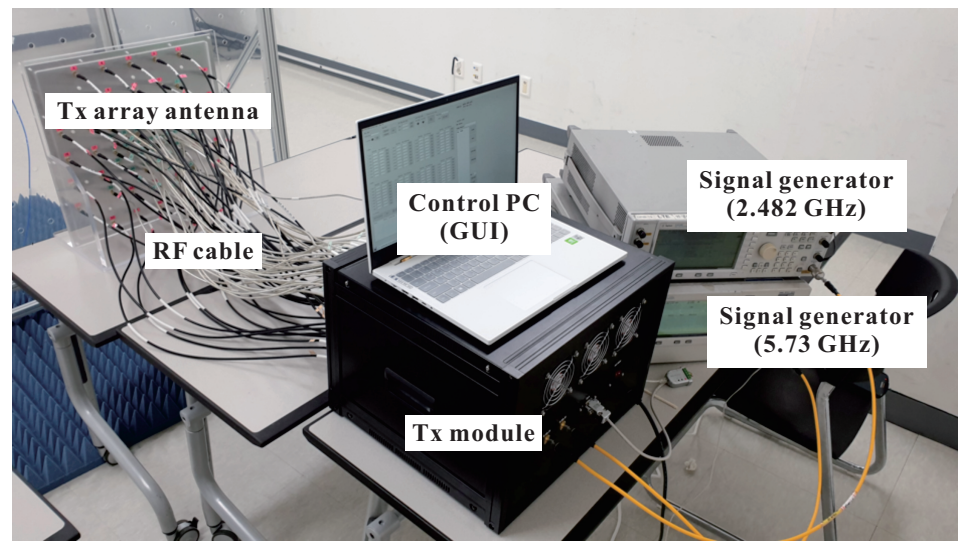

Figure 9. Implemented dual-band Tx system. 


\subsection{Design of the Rx Antennas}

In order to conduct various WPT experiments according to the operating frequency, as shown in Figure 1, three types of antennas are implemented as Rx antennas: a 2.4GHz patch antenna, a $5.8 \mathrm{GHz}$ patch antenna, and a dual-band (operating at 2.4 and $5.8 \mathrm{GHz}$ ) patch antenna. For polarization matching with the Tx array antenna, all of these Rx antennas are designed to operate RHCP at their respective operating frequencies.

\subsection{GHz Patch}

The configuration of the $2.4 \mathrm{GHz}$ Rx antenna is equal to that shown in Figure 3a, and Figure 10 shows the simulated and measured results of this single patch. According to the measured result, the $-10 \mathrm{~dB}$ reflection coefficient bandwidth is $2.44-2.52 \mathrm{GHz}$. In addition, the RHCP gain and AR in the $+z$-direction at $2.482 \mathrm{GHz}$ are measured as $6.04 \mathrm{dBic}$ and $2.7 \mathrm{~dB}$, respectively, and $3 \mathrm{~dB}$ AR bandwidth is $2.467-2.483 \mathrm{GHz}$. The simulated and measured results are in good agreement.

\subsection{GHz Patch}

The $5.8 \mathrm{GHz} \mathrm{Rx}$ antenna for receiving wireless power of $5.73 \mathrm{GHz}$ is presented in Figure $3 \mathrm{~b}$. As shown in Figure 11, the simulated and measured results demonstrate that the $-10 \mathrm{~dB}$ reflection coefficient bandwidth of this antenna is $5.60-5.87 \mathrm{GHz}$. At $5.73 \mathrm{GHz}$, its RHCP gain in the $+z$-direction is $6.64 \mathrm{dBic}$, AR is $1.58 \mathrm{~dB}$, and the $3 \mathrm{~dB}$ AR bandwidth is $5.665-5.755 \mathrm{GHz}$. These measured results are in good agreement with the simulated results.

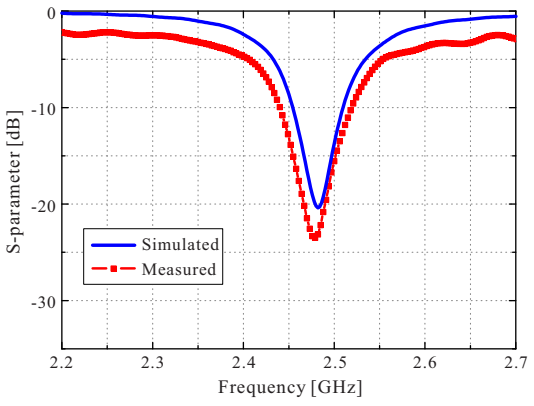

(a)

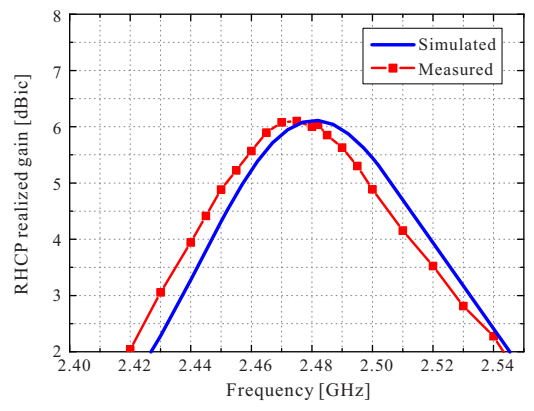

(b)

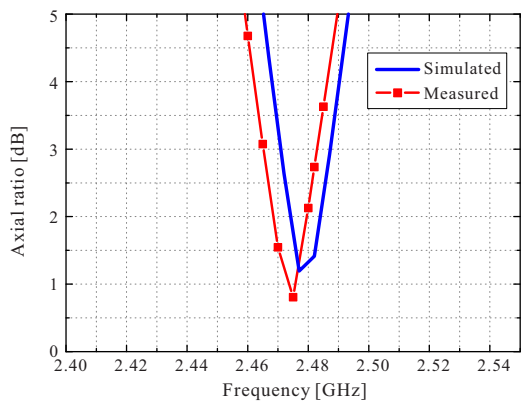

(c)

Figure 10. Simulated and measured results of the $2.4 \mathrm{GHz}$ patch antenna: (a) reflection coefficients; (b) realized gain; (c) axial ratio.

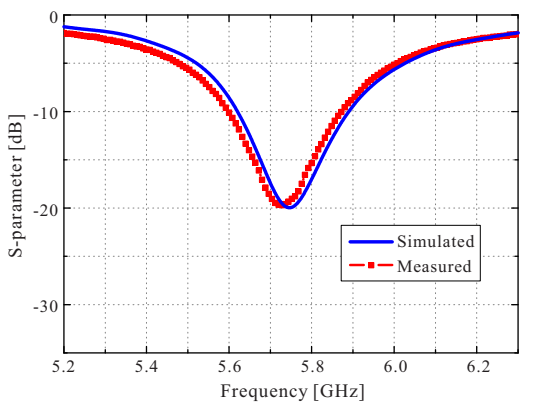

(a)

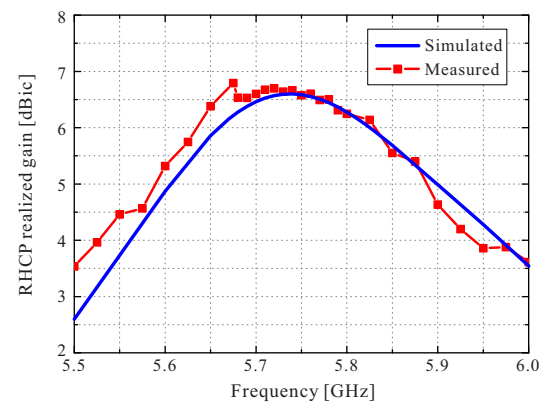

(b)

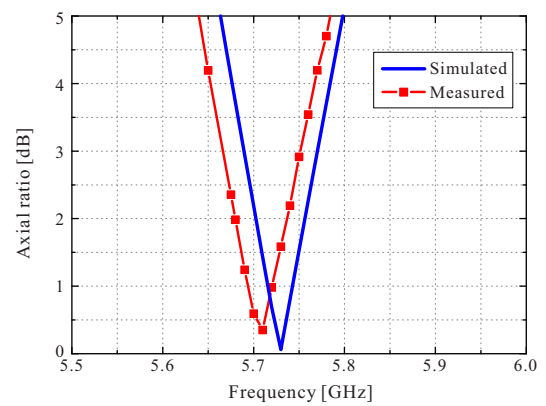

(c)

Figure 11. Simulated and measured results of the $5.8 \mathrm{GHz}$ patch antenna: (a) reflection coefficients; (b) realized gain; (c) axial ratio.

\subsubsection{Dual-Band (2.4 and 5.8 GHz) Patch}

The dual-band Rx antenna for receiving the dual-band wireless power of 2.4 and $5.8 \mathrm{GHz}$ is described in Figure 12. This antenna consists of a stacked two-layer substrate, a ground plane, a $2.4 \mathrm{GHz}$ RHCP patch, and a $5.8 \mathrm{GHz}$ RHCP patch with a truncated square structure [36]. On the top layer (Layer-1), the $5.8 \mathrm{GHz}$ patch is located, and it is directly 
fed through a metal via. The $2.4 \mathrm{GHz}$ patch is on Layer-2 and is fed by a coupling feeding method with the metal via. This $2.4 \mathrm{GHz}$ patch is rotated $50^{\circ}$ counterclockwise around the metal via in order to reduce mutual interference with the $5.8 \mathrm{GHz}$ patch and to improve the radiation pattern. Both stacked substrates in this antenna are the RF-35 types $\left(\varepsilon_{r}=3.5\right.$, $\tan \delta=0.0018$ ) with a thickness of $1.52 \mathrm{~mm}$. Figure 13 shows the simulated and measured results of the dual-band Rx antenna in Figure 12. The measured reflection coefficients are $-13.93 \mathrm{~dB}$ at $2.482 \mathrm{GHz}$ and $-11.48 \mathrm{~dB}$ at $5.73 \mathrm{GHz}$. The measured results of the AR are $2.5 \mathrm{~dB}$ and $0.54 \mathrm{~dB}$ at $2.482 \mathrm{GHz}$ and $5.73 \mathrm{GHz}$, respectively. AR bandwidths less than $3 \mathrm{~dB}$ are also achieved as $2.481-2.505 \mathrm{GHz}$ and $5.682-5.788 \mathrm{GHz}$. The RHCP-realized gain in the $+z$-direction is measured and found to be $5.01 \mathrm{dBic}$ at $2.482 \mathrm{GHz}$ and $6.27 \mathrm{dBic}$ at $5.73 \mathrm{GHz}$.
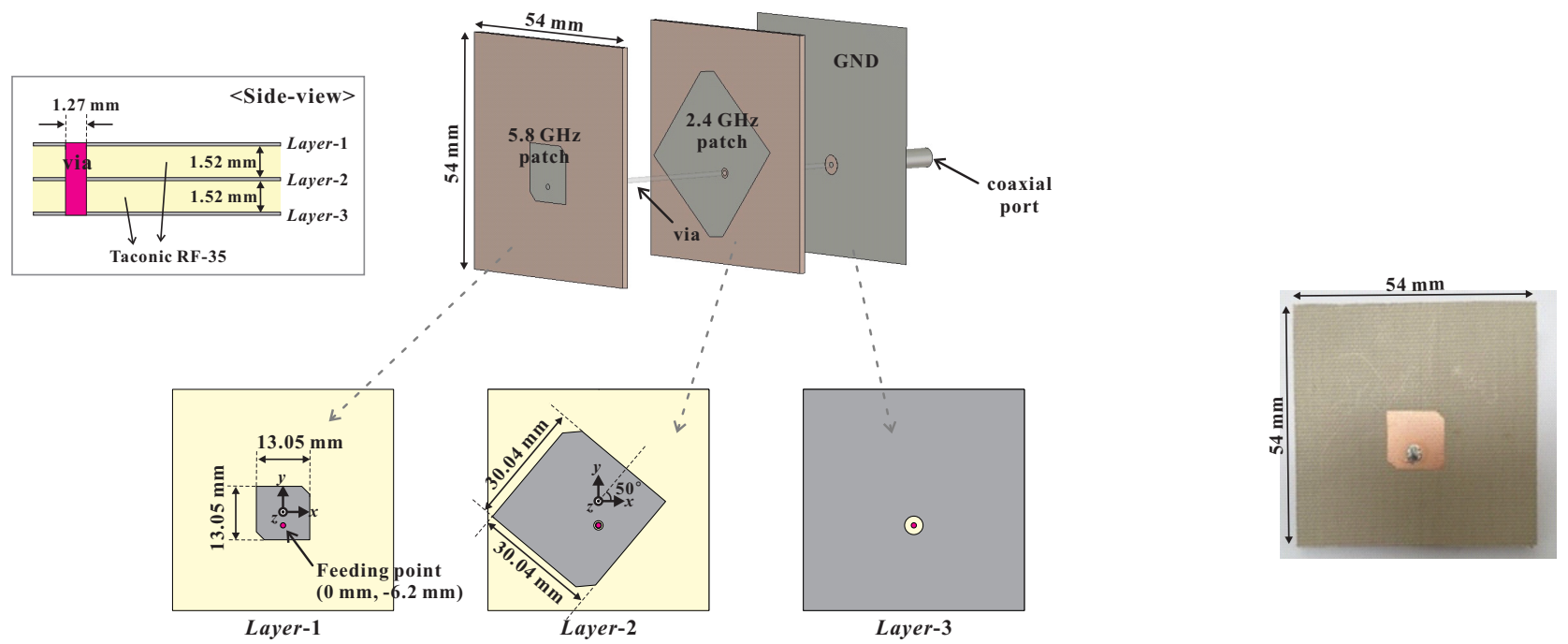

(a)

(b)

Figure 12. Dual-band (2.4 and 5.8 GHz) stacked patch antenna: (a) configuration; (b) top view of the fabricated antenna.

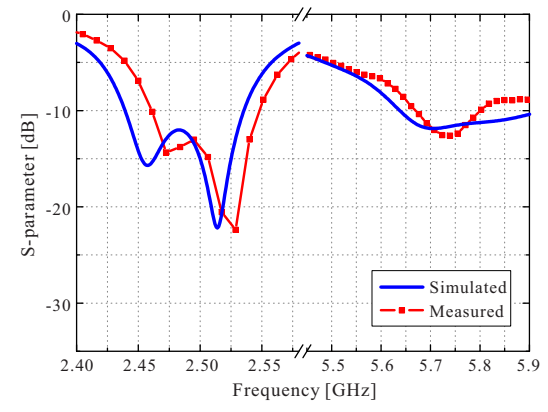

(a)

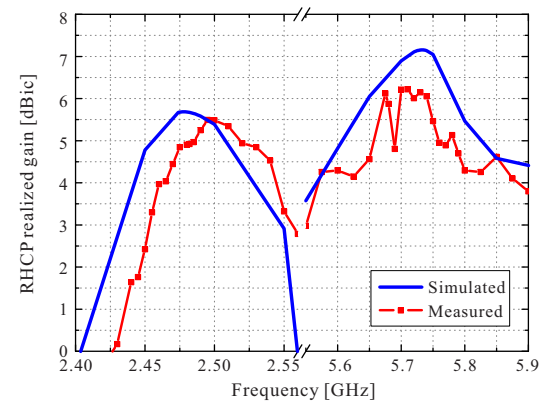

(b)

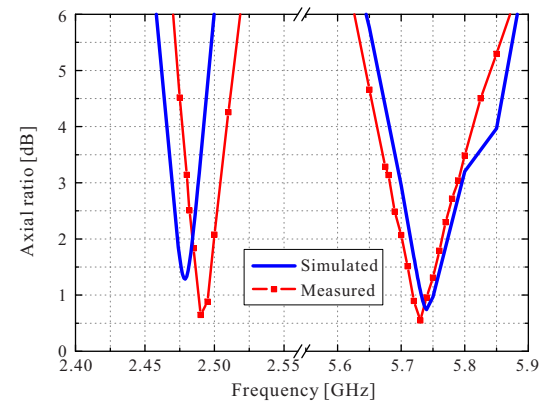

(c)

Figure 13. Simulated and measured results of the dual-band patch antenna: (a) reflection coefficients; (b) realized gain; (c) axial ratio.

\section{Experimental Results of RF Wireless Power Transmission}

\subsection{Single-Band RF WPT Experiment}

RF WPT experiments using the single-band (either 2.4 or $5.8 \mathrm{GHz}$ ) were conducted, as shown in Figure 1a,b, using the developed dual-band RF WPT system presented in Section 2. During the RF WPT experiment using the frequency of $2.482 \mathrm{GHz}$, every $2.4 \mathrm{GHz}$ radiating element in the Tx array was on and every $5.8 \mathrm{GHz}$ radiating element was off (specifically, they are terminated by $50 \Omega$ ). Likewise, during the experiment of transmitting $5.73 \mathrm{GHz}$ power, every $5.8 \mathrm{GHz}$ element in the Tx array was on and every $2.4 \mathrm{GHz}$ element was off. The on or off state of the radiating elements in the Tx array can be adjusted using 
a GUI program on a control PC connected to the Tx module. In the RF WPT experiment, the RF wireless power received by the Rx antenna was measured using an Agilent E4440A spectrum analyzer. Finally, the measured results are compared with the calculated results using Equation (4).

\subsubsection{WPT Experiment (1): Varying the Transmission Distance}

First, as shown in Figure 14, the Rx antenna, which is either the $2.4 \mathrm{GHz}$ patch antenna in Figure $3 a$ or the $5.8 \mathrm{GHz}$ patch antenna in Figure $3 \mathrm{~b}$, was located in front of the Tx. With a change of the transmission distance between the Tx and Rx from $1 \mathrm{~m}$ to $3.92 \mathrm{~m}$, the received power was measured. When RF power of $2.482 \mathrm{GHz}$ was transmitted to the $\mathrm{Rx}$, as shown in Figure 2a, which is located at the front of the Tx, the results of the measured received power by the Rx antenna according to the distance are shown in Figure 15a and Table 2. Here, the power transmitted by each $2.4 \mathrm{GHz}$ radiating element in the Tx array is equal to $25 \mathrm{dBm}$ and the total transmitted power is $40 \mathrm{dBm}(=10 \mathrm{~W})$ for $2.482 \mathrm{GHz}$. The distance of $1-3.92 \mathrm{~m}$ at $2.482 \mathrm{GHz}$ is within the Fresnel area $(0.85-6.12 \mathrm{~m})$ based on the $2.4 \mathrm{GHz}$ thinned array. To operate beam-forming and beam-focusing, the phases of the excited signal of each radiating element are adjusted by the GUI. According to the experimental results, as the distance was increased, there was no significant difference in the received power by beam-forming (in this case, the excited phase is the in-phase) or beam-focusing (applied excited phase calculated by Equation (3)). However, as the distance between the Tx and the Rx decreased, the received power by beam-focusing was prominently higher than that by beam-forming. In particular, when the beam is focused to a point at a distance of $1 \mathrm{~m}$, the measured received power was approximately $0.7 \mathrm{dBm}$ higher than when beam-forming was applied.

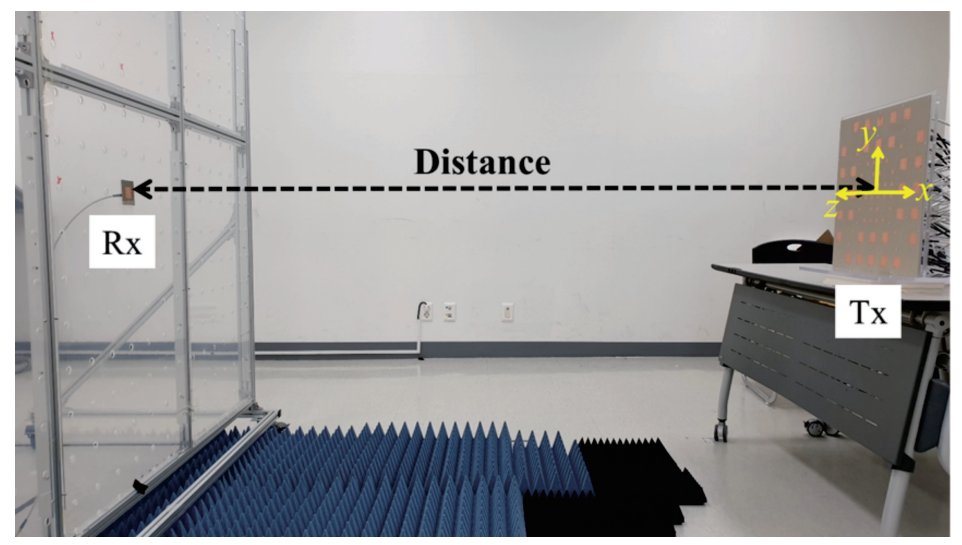

Figure 14. RF WPT experimental set-up (1): according to the transmission distance.

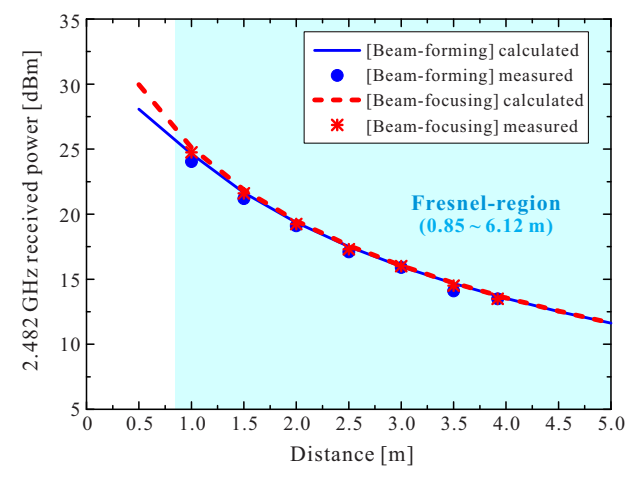

(a)

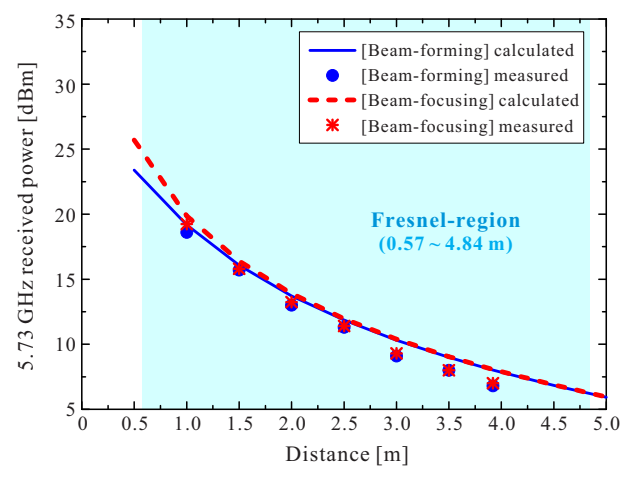

(b)

Figure 15. Measured and calculated results of the received power according to the transmission distance: (a) $2.482 \mathrm{GHz}$; (b) $5.73 \mathrm{GHz}$. 
When the $5.8 \mathrm{GHz}$ Rx shown in Figure $2 \mathrm{~b}$ is located at the front of the Tx, Figure $15 \mathrm{~b}$ and Table 3 present the results of an experiment in which $5.73 \mathrm{GHz}$ wireless power is transmitted to the $\mathrm{Rx}$. The magnitude of the power radiated by each $5.8 \mathrm{GHz}$ radiating element in the Tx array is equal to $25 \mathrm{dBm}$ and the total transmitted power is $40 \mathrm{dBm}$ $(=10 \mathrm{~W})$ at $5.73 \mathrm{GHz}$. The distance of $1-3.92 \mathrm{~m}$ at $5.73 \mathrm{GHz}$ is within the Fresnel area $(0.57-4.84 \mathrm{~m})$ based on the $5.8 \mathrm{GHz}$ thinned array. In this experiment, when the excited phase for beam-focusing was applied in the Tx array, the received power was measured and found to be higher by approximately $0.25 \mathrm{dBm}$ compared to that when applying the beamforming method, on average. Consequently, the measured results of the received power were in good agreement with the results calculated using Equation (4), indicating that the implemented WPT system was appropriately established and that the WPT experiment was conducted well. According to the measured results of the received power by applying the beam-focusing, the WPT efficiencies at the $2.482 \mathrm{GHz}$ and $5.73 \mathrm{GHz}$ are distributed as $2.985-0.224 \%$ and $0.841-0.050 \%$, respectively, when the distance varies from $1 \mathrm{~m}$ to $3.92 \mathrm{~m}$. It is believed that a slight measurement arose due to the indoor experimental environment and the inaccuracy of the Rx position.

Table 2. Experimental results of $2.482 \mathrm{GHz}$ received power when total transmitted power is $40 \mathrm{dBm}(=10 \mathrm{~W})$.

\begin{tabular}{ccccc}
\hline \multirow{2}{*}{ Distance } & \multicolumn{2}{c}{$\begin{array}{c}\text { Beam-Forming } \\
\text { (In-Phase) }\end{array}$} & Calculated & Beam-Focusing \\
\cline { 2 - 5 } & Calculated & Measured & Measured \\
\hline $\mathbf{1} \mathbf{~ m}$ & $24.63 \mathrm{dBm}(0.2904 \mathrm{~W})$ & $24.05 \mathrm{dBm}(0.2541 \mathrm{~W})$ & $25.13 \mathrm{dBm}(0.3258 \mathrm{~W})$ & $24.75 \mathrm{dBm}(0.2985 \mathrm{~W})$ \\
$\mathbf{1 . 5} \mathbf{~ m}$ & $21.65 \mathrm{dBm}(0.1462 \mathrm{~W})$ & $21.20 \mathrm{dBm}(0.1318 \mathrm{~W})$ & $21.87 \mathrm{dBm}(0.1538 \mathrm{~W})$ & $21.60 \mathrm{dBm}(0.1445 \mathrm{~W})$ \\
$\mathbf{2} \mathbf{~ m}$ & $19.36 \mathrm{dBm}(0.0863 \mathrm{~W})$ & $19.10 \mathrm{dBm}(0.0813 \mathrm{~W})$ & $19.49 \mathrm{dBm}(0.0889 \mathrm{~W})$ & $19.25 \mathrm{dBm}(0.0841 \mathrm{~W})$ \\
$\mathbf{2 . 5} \mathbf{~ m}$ & $17.51 \mathrm{dBm}(0.0564 \mathrm{~W})$ & $17.10 \mathrm{dBm}(0.0513 \mathrm{~W})$ & $17.59 \mathrm{dBm}(0.0574 \mathrm{~W})$ & $17.30 \mathrm{dBm}(0.0537 \mathrm{~W})$ \\
$\mathbf{3} \mathbf{~ m}$ & $15.98 \mathrm{dBm}(0.0396 \mathrm{~W})$ & $15.90 \mathrm{dBm}(0.0389 \mathrm{~W})$ & $16.04 \mathrm{dBm}(0.0402 \mathrm{~W})$ & $16.00 \mathrm{dBm}(0.0398 \mathrm{~W})$ \\
$\mathbf{3 . 5} \mathbf{~ m}$ & $14.67 \mathrm{dBm}(0.0293 \mathrm{~W})$ & $14.10 \mathrm{dBm}(0.0257 \mathrm{~W})$ & $14.72 \mathrm{dBm}(0.0296 \mathrm{~W})$ & $14.50 \mathrm{dBm}(0.0282 \mathrm{~W})$ \\
$\mathbf{3 . 9 2} \mathbf{~ m}$ & $13.71 \mathrm{dBm}(0.0235 \mathrm{~W})$ & $13.50 \mathrm{dBm}(0.0224 \mathrm{~W})$ & $13.74 \mathrm{dBm}(0.0237 \mathrm{~W})$ & $13.50 \mathrm{dBm}(0.0224 \mathrm{~W})$ \\
\hline
\end{tabular}

Table 3. Experimental results of $5.73 \mathrm{GHz}$ received power when total transmitted power is $40 \mathrm{dBm}(=10 \mathrm{~W})$.

\begin{tabular}{|c|c|c|c|c|}
\hline \multirow[t]{2}{*}{ Distance } & \multicolumn{2}{|c|}{$\begin{array}{l}\text { Beam-Forming } \\
\text { (In-Phase) }\end{array}$} & \multicolumn{2}{|c|}{ Beam-Focusing } \\
\hline & Calculated & Measured & Calculated & Measured \\
\hline $1 \mathrm{~m}$ & $19.18 \mathrm{dBm}(0.0828 \mathrm{~W})$ & $18.60 \mathrm{dBm}(0.0724 \mathrm{~W})$ & $19.87 \mathrm{dBm}(0.0971 \mathrm{~W})$ & $19.25 \mathrm{dBm}(0.0841 \mathrm{~W})$ \\
\hline $1.5 \mathrm{~m}$ & $16.07 \mathrm{dBm}(0.0405 \mathrm{~W})$ & $15.70 \mathrm{dBm}(0.0372 \mathrm{~W})$ & $16.39 \mathrm{dBm}(0.0436 \mathrm{~W})$ & $15.80 \mathrm{dBm}(0.0380 \mathrm{~W})$ \\
\hline $2 \mathrm{~m}$ & $13.72 \mathrm{dBm}(0.0236 \mathrm{~W})$ & $13.00 \mathrm{dBm}(0.0200 \mathrm{~W})$ & $13.90 \mathrm{dBm}(0.0245 \mathrm{~W})$ & $13.25 \mathrm{dBm}(0.0211 \mathrm{~W})$ \\
\hline $2.5 \mathrm{~m}$ & $11.85 \mathrm{dBm}(0.0153 \mathrm{~W})$ & $11.30 \mathrm{dBm}(0.0135 \mathrm{~W})$ & $11.97 \mathrm{dBm}(0.0157 \mathrm{~W})$ & $11.40 \mathrm{dBm}(0.0138 \mathrm{~W})$ \\
\hline $3 \mathrm{~m}$ & $10.31 \mathrm{dBm}(0.0107 \mathrm{~W})$ & $9.10 \mathrm{dBm}(0.0081 \mathrm{~W})$ & $10.39 \mathrm{dBm}(0.0109 \mathrm{~W})$ & $9.30 \mathrm{dBm}(0.0085 \mathrm{~W})$ \\
\hline $3.5 \mathrm{~m}$ & 8.99 dBm (0.0079 W) & $8.00 \mathrm{dBm}(0.0063 \mathrm{~W})$ & $9.05 \mathrm{dBm}(0.0080 \mathrm{~W})$ & $8.00 \mathrm{dBm}(0.0063 \mathrm{~W})$ \\
\hline $3.92 \mathrm{~m}$ & $8.02 \mathrm{dBm}(0.0063 \mathrm{~W})$ & $6.80 \mathrm{dBm}(0.0048 \mathrm{~W})$ & 8.07 dBm $(0.0064 \mathrm{~W})$ & $7.00 \mathrm{dBm}(0.0050 \mathrm{~W})$ \\
\hline
\end{tabular}

\subsubsection{WPT Experiment (2): Varying the Rx Position and the Direction of Beam-Forming}

The RF WPT experiment at 2.482 and $5.73 \mathrm{GHz}$ was conducted by changing the position of the Rx antenna on a virtual plane with a spacing of $0.3 \mathrm{~m}$ at a distance of $1 \mathrm{~m}$ or $2 \mathrm{~m}$, as shown in Figure 16. At this time, the power received by the Rx antenna according to the beam-steering method (i.e., either beam-forming or beam-focusing) was measured. In the $2.482 \mathrm{GHz}$ WPT experiment, the $2.4 \mathrm{GHz}$ patch antenna shown in Figure 2a was applied as the Rx and the total transmitted power at $2.482 \mathrm{GHz}$ is $40 \mathrm{dBm}(=10 \mathrm{~W})$ with power uniformly radiated by the 32 elements. Figure 17 shows the distribution of the $2.482 \mathrm{GHz}$ received power by the $\mathrm{Rx}$ antenna when transmitting $2.482 \mathrm{GHz}$ power to various Rx positions, as depicted in Figure 16, depending on whether beam-forming or 
beam-focusing is used. The received power when applying beam-focusing was higher than that with beam-forming, and these results were more remarkable when the transmission distance was $1 \mathrm{~m}$ (see Figure 17a) compared to $2 \mathrm{~m}$ (see Figure 17b). When applying the beam-focusing at $2.482 \mathrm{GHz}$, the WPT efficiencies at $1 \mathrm{~m}$ and $2 \mathrm{~m}$ have a range of $2.985-0.257 \%$ and $0.841-0.316 \%$, respectively. It can also be seen the measured and calculated results were well matched, indicating that the RF WPT experiment was feasible using the implemented system.

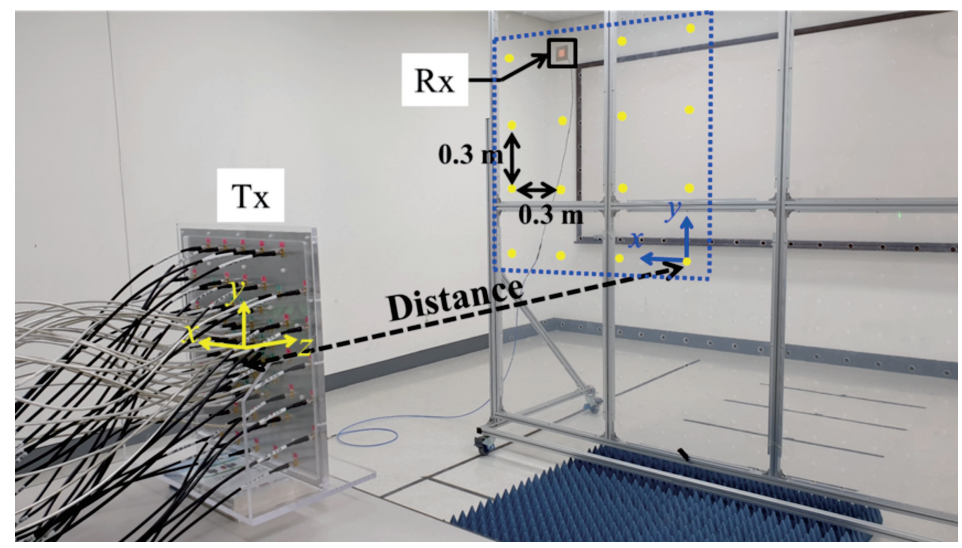

Figure 16. RF WPT experimental set-up (2): according to the Rx position.

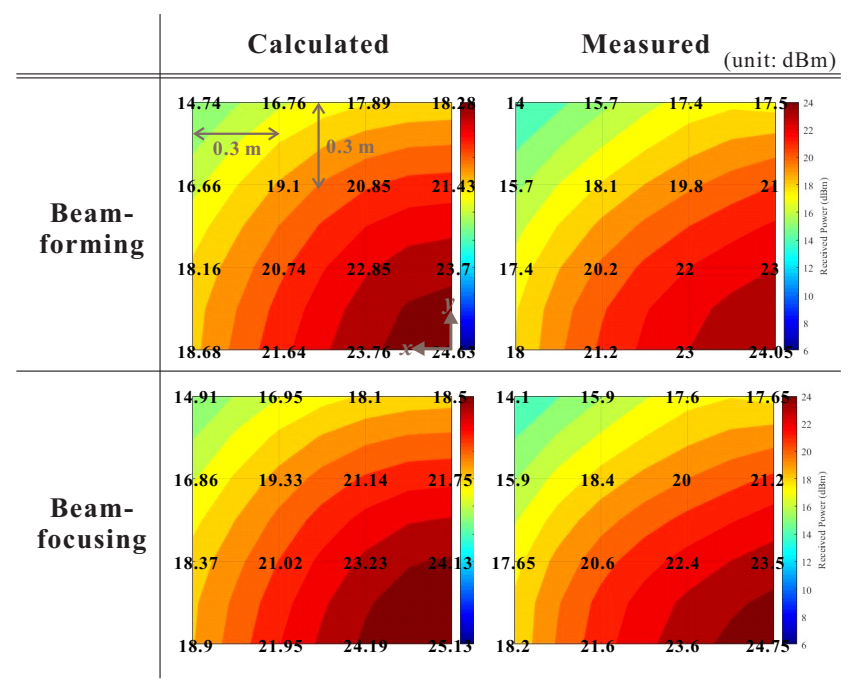

(a)

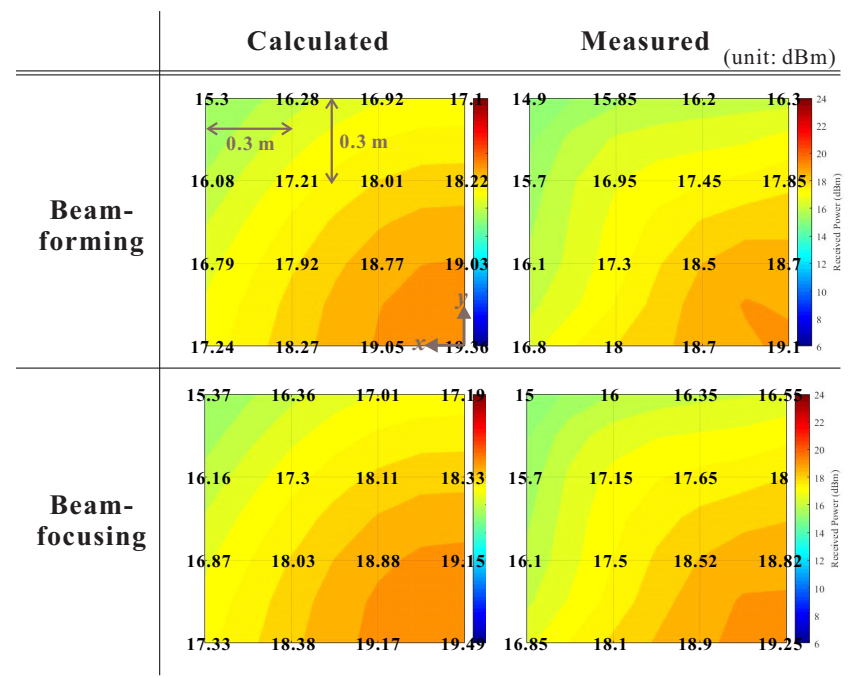

(b)

Figure 17. Distribution of the $2.482 \mathrm{GHz}$ received power according to the Rx position: $(\mathbf{a})$ distance $=1 \mathrm{~m}$; $(\mathbf{b})$ distance $=2 \mathrm{~m}$.

As a result of the $5.73 \mathrm{GHz}$ WPT experiment, Figure 18a,b shows the received power distribution when the Rx antenna, as in Figure $2 b$, is moved on a virtual plane at a distance of $1 \mathrm{~m}$ or $2 \mathrm{~m}$, as shown in Figure 16, and $5.73 \mathrm{GHz}$ wireless power of $40 \mathrm{dBm}$ is transmitted to this Rx antenna. It can be seen that higher transmission efficiency is measured when applying beam-focusing rather than beam-forming. From the measured results of the $5.73 \mathrm{GHz}$ received power with beam-focusing, the WPT efficiencies at $1 \mathrm{~m}$ and $2 \mathrm{~m}$ are distributed as $0.841-0.060 \%$ and $0.211-0.072 \%$, respectively. In other words, the overall result for $5.73 \mathrm{GHz}$ received power (Figure 18) was lower than that for $2.482 \mathrm{GHz}$ received power (Figure 17) because the higher frequency causes greater losses in free space. According to the results in Figures 17 and 18, the error between the calculated and measured results increased slightly when the position of the Rx deviated from the center. This is considered to be a measurement error (difficulties in accurately setting the location 
of the Rx when fixing the Rx antenna due to cable tension, among others issues), which arose during the experiment in the indoor environment used in this study.

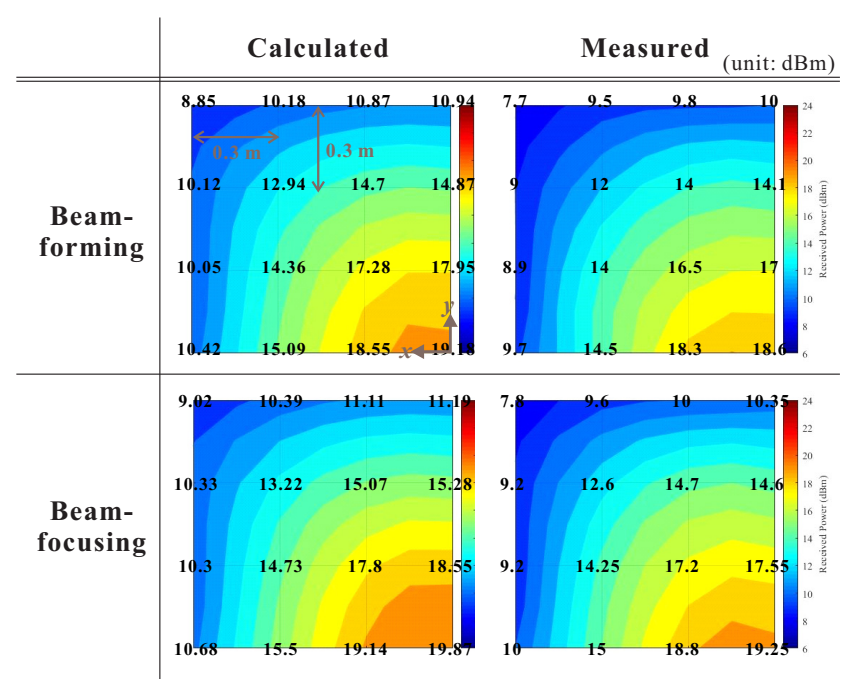

(a)

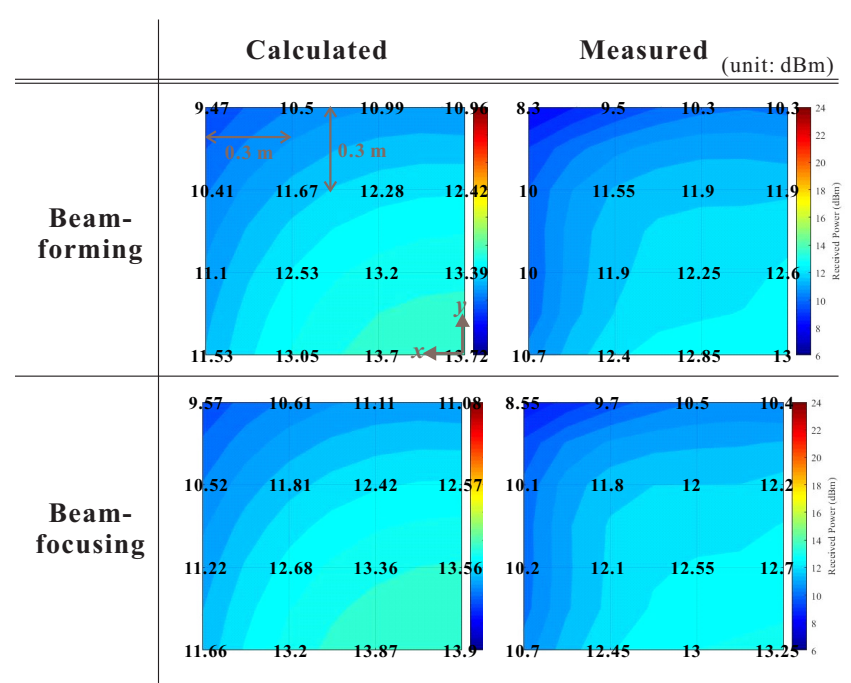

(b)

Figure 18. Distribution of the $5.73 \mathrm{GHz}$ received power according to the Rx position:(a) distance $=1 \mathrm{~m} ;(\mathbf{b})$ distance $=2 \mathrm{~m}$.

\subsection{Dual-Band (2.4 and 5.8 GHz) RF WPT Experiment}

\subsubsection{WPT Experiment (3): With a Dual-Band Rx Antenna}

To verify whether the developed dual-band RF WPT system transmits dual-band wireless power simultaneously, as shown in Figure 1c, a dual-band RF WPT experiment was conducted with the dual-band Rx in Figure 12. This Rx antenna was positioned at the point of $x^{\prime}=0, y^{\prime}=0$, and $z^{\prime}=1$. The total transmitted power of $2.482 \mathrm{GHz}$ and $5.73 \mathrm{GHz}$ was $8 \mathrm{~W}(=39 \mathrm{dBm})$ and $2 \mathrm{~W}(=33 \mathrm{dBm})$, respectively, and wireless power at both 2.482 and $5.73 \mathrm{GHz}$ was radiated simultaneously with two focused beams. The dual-band power received by the $R x$ antenna was measured through a spectrum analyzer. The screen of the spectrum analyzer used at that time is shown in Figure 19. From this result, it can be seen that dual-band RF wireless power of 2.482 and $5.73 \mathrm{GHz}$ could successfully be transmitted and received at the same time.

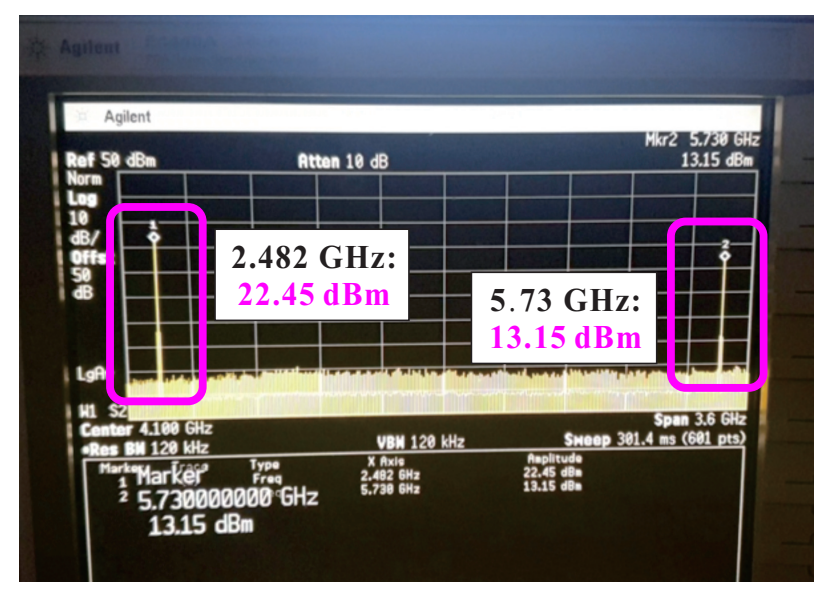

Figure 19. Screen of the spectrum analyzer when transmitting 2.482 and $5.73 \mathrm{GHz}$ RF power to a dual-band Rx antenna.

Table 4 presents the measured results of the dual-band received power according to the beam-steering method. When the beam was focused on the Rx position, the measured 
2.482 GHz received power was $22.45 \mathrm{dBm}$ (WPT efficiency $=2.197 \%$ ) and the measured $5.73 \mathrm{GHz}$ received power was $13.15 \mathrm{dBm}$ (WPT efficiency $=1.033 \%$ ), meaning that these received power levels at 2.482 and $5.73 \mathrm{GHz}$ were correspondingly $0.15 \mathrm{~dB}$ and $0.55 \mathrm{~dB}$ higher than those by beam-forming. Because the distance of $1 \mathrm{~m}$ is in the Fresnel region for the $2.4 \mathrm{GHz}$ and $5.8 \mathrm{GHz}$ thinned arrays, the effect of beam-focusing may be outstanding here. Moreover, these measured results are in good agreement with the calculated results using Equation (4).

Table 4. Experimental results of the received power when transmitting dual-band power to a dual-band Rx antenna.

\begin{tabular}{ccccc}
\hline \multirow{2}{*}{$\begin{array}{c}\text { Received } \\
\text { Power }\end{array}$} & \multicolumn{4}{c}{ Rx: Dual-Band Antenna } \\
\cline { 2 - 5 } & Calculated & Measured & Calculated & Measured \\
\cline { 2 - 5 } & $23.73 \mathrm{GHz}$ \\
\hline $\begin{array}{c}\text { Beam-forming } \\
\text { (in-phase) }\end{array}$ & $23.13 \mathrm{dBm}$ & $22.3 \mathrm{dBm}$ & $12.92 \mathrm{dBm}$ & $12.6 \mathrm{dBm}$ \\
Beam-focusing & $23.55 \mathrm{dBm}$ & $22.45 \mathrm{dBm}$ & $13.46 \mathrm{dBm}$ & $13.15 \mathrm{dBm}$ \\
\hline
\end{tabular}

3.2.2. WPT Experiment (4): With Two Rx Antennas Operating at Two Different Frequencies

The dual-band RF WPT experiment shown in Figure 1d was carried out. Here, dual beams of $2.482 \mathrm{GHz}$ and $5.73 \mathrm{GHz}$ were formed individually and transmitted to two receivers $(\operatorname{Rx}(1)$ and $\operatorname{Rx}(2))$ located at different positions, as described in Figure 20; $\operatorname{Rx}(1)$ is a $2.4 \mathrm{GHz} \mathrm{Rx}$ antenna, shown in Figure $2 \mathrm{a}$, and exists at $x^{\prime}=0.6 \mathrm{~m}, y^{\prime}=0$, and $z^{\prime}=2.5 \mathrm{~m}$, including the Fresnel region of the $2.4 \mathrm{GHz}$ Tx thinned array. $\mathrm{Rx}(2)$ is the $5.8 \mathrm{GHz} \mathrm{Rx}$ antenna shown in Figure $2 \mathrm{~b}$ and is at $x^{\prime}=0, y^{\prime}=0.6 \mathrm{~m}$, and $z^{\prime}=2.5 \mathrm{~m}$ in the Fresnel region of the $5.8 \mathrm{GHz} \mathrm{Tx}$ thinned array. In this experiment, $2.482 \mathrm{GHz}$ wireless power of $40 \mathrm{dBm}$ and $5.73 \mathrm{GHz}$ wireless power of $40 \mathrm{dBm}$ were radiated separately in the directions of $\operatorname{Rx}(1)$ and $\mathrm{Rx}(2)$, respectively. When the 2.482 and $5.73 \mathrm{GHz} \mathrm{RF}$ power was transmitted with focused beams, the power levels received through $\operatorname{Rx}(1)$ and $\operatorname{Rx}(2)$ were measured by spectrum analyzers. The measured results of the received power at 2.482 and $5.73 \mathrm{GHz}$ were $15.57 \mathrm{dBm}$ and $10.58 \mathrm{dBm}$, respectively (see Table 5). Accordingly, the proposed dual-band RF WPT system allows wireless power transfers to two receivers at different positions by forming dual beam with different and seperate operating frequencies.

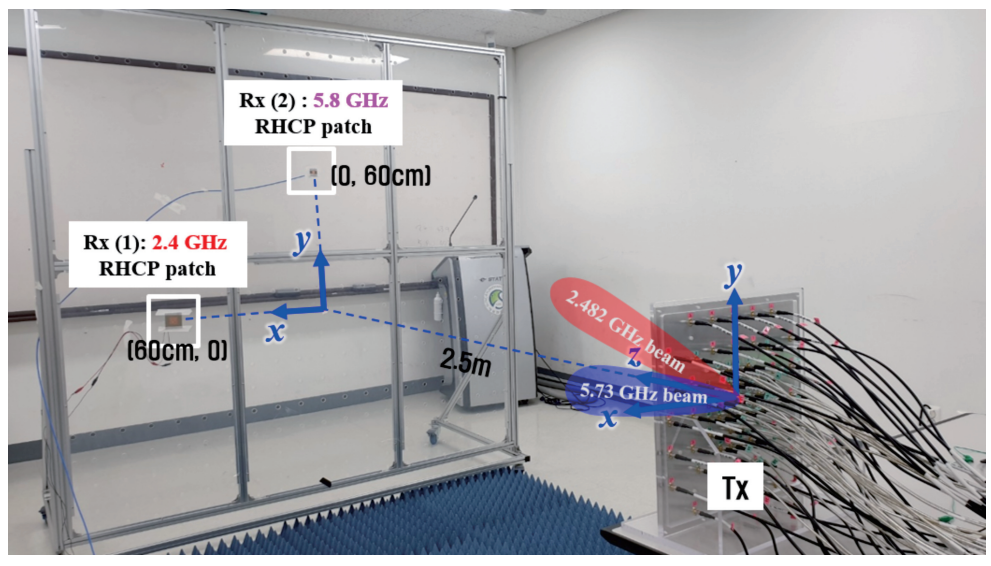

Figure 20. Dual-band RF WPT experiment set-up for transmitting 2.482 and $5.73 \mathrm{GHz}$ RF power separately to two received antennas. 
Table 5. Experimental result of the dual-band received power when transmitting a dual beam separately to two receiving antennas.

\begin{tabular}{ccccc}
\hline \multirow{2}{*}{ Beam-Focusing } & \multicolumn{2}{c}{$\mathbf{R x}(\mathbf{1}): \mathbf{2 . 4} \mathbf{~ G H z}$ Patch } & \multicolumn{2}{c}{$\mathbf{R x}(\mathbf{2}): 5.8 \mathrm{GHz}$ Patch } \\
\cline { 2 - 5 } & \multicolumn{2}{c}{$\mathbf{2 . 4 8 2} \mathbf{G H z}$} & \multicolumn{2}{c}{$\mathbf{5 . 7 3} \mathbf{G H z}$} \\
\cline { 2 - 5 } & Calculated & Measured & Calculated & Measured \\
\hline Received power & $16.57 \mathrm{dBm}$ & $15.57 \mathrm{dBm}$ & $11.47 \mathrm{dBm}$ & $10.58 \mathrm{dBm}$ \\
(WPT efficiency) & $(0.454 \%)$ & $(0.361 \%)$ & $(0.140 \%)$ & $(0.114 \%)$ \\
\hline
\end{tabular}

Table 6 shows comparisons of the developed system in this study with previous studies related to the RF WPT system. Frequency, polarization, sizes of the Tx and Rx antennas, total transmitted power $\left(P_{T}\right)$, distance, total received power $\left(P_{R}\right)$, and the WPT efficiency are compared here. Although the measured results of the WPT efficiency in $[7,8]$ was relatively high, the sizes Tx and Rx antenna in these WPT systems are relatively larger. According to Table 6, it is revealed that dual-band RF WPT system developed in this study has distinction compared to previous RF WPT systems using single-band frequency.

Table 6. Comparisons of previous studies of RF WPT.

\begin{tabular}{|c|c|c|c|c|c|c|c|}
\hline & Frequency & Polarization & $\begin{array}{c}\text { Size of } \\
\text { Tx Antenna }\end{array}$ & $P_{T}$ & Distance & $\begin{array}{c}\text { Size of } \\
\text { Rx Antenna }\end{array}$ & $\begin{array}{c}P_{R} \\
\text { (WPT Efficiency) }\end{array}$ \\
\hline [7] & $5.8 \mathrm{GHz}$ & $\begin{array}{c}\text { LP } \\
\text { (linear polarization) }\end{array}$ & $1 \times 1 \mathrm{~m}^{2}$ & $500 \mathrm{~W}$ & $10 \mathrm{~m}$ & $1 \times 1 \mathrm{~m}^{2}$ & $\begin{array}{l}209.26 \mathrm{~W} \\
(41.85 \%)\end{array}$ \\
\hline [8] & $2.45 \mathrm{GHz}$ & $\mathrm{LP}$ & $1 \times 0.122 \mathrm{~m}^{2}$ & $0.25 \mathrm{~W}$ & $1 \mathrm{~m}$ & $0.5 \times 0.122 \mathrm{~m}^{2}$ & $\begin{array}{c}0.0125 \mathrm{~W} \\
(5.01 \%)\end{array}$ \\
\hline [37] & $2.08 \mathrm{GHz}$ & LP & $\begin{array}{l}0.28 \times 0.1 \mathrm{~m}^{2} \\
\quad(\text { guess })\end{array}$ & $1 \mathrm{~W}$ & $0.5 \mathrm{~m}$ & $\begin{array}{c}0.07 \times 0.1 \mathrm{~m}^{2} \\
\quad \text { (guess) }\end{array}$ & $\begin{array}{c}0.014 \mathrm{~W} \\
(1.4 \%)\end{array}$ \\
\hline [38] & $5.8 \mathrm{GHz}$ & $\mathrm{LP}$ & $0.217 \times 0.217 \mathrm{~m}^{2}$ & $0.1 \mathrm{~W}$ & $0.4 \mathrm{~m}$ & $0.16 \times 0.16 \mathrm{~m}^{2}$ & $\begin{array}{l}0.0332 \mathrm{~W} \\
(0.332 \%)\end{array}$ \\
\hline This study & $\begin{array}{l}2.482 \mathrm{GHz} \\
5.73 \mathrm{GHz}\end{array}$ & $\begin{array}{c}\mathrm{CP} \\
\text { (circular polarization) }\end{array}$ & $0.44 \times 0.44 \mathrm{~m}^{2}$ & $\begin{array}{l}10 \mathrm{~W} \\
10 \mathrm{~W}\end{array}$ & $1-3.92 \mathrm{~m}$ & $\begin{array}{l}0.063 \times 0.063 \mathrm{~m}^{2} \\
0.031 \times 0.031 \mathrm{~m}^{2}\end{array}$ & $\begin{array}{c}0.2985 \mathrm{~W}-0.0224 \mathrm{~W} \\
(2.985-0.224 \%) \\
0.0841 \mathrm{~W}-0.005 \mathrm{~W} \\
(0.841-0.05 \%)\end{array}$ \\
\hline
\end{tabular}

\section{Conclusions}

In this paper, a dual-band RF WPT system that includes a shared-aperture 2.4 and $5.8 \mathrm{GHz}$ Tx array antenna with $2.4 \mathrm{GHz}$ RHCP patches and $5.8 \mathrm{GHz}$ RHCP patches is developed. The Tx array antenna combining a $2.4 \mathrm{GHz}$ thinned array and a $5.8 \mathrm{GHz}$ thinned array is optimally designed to obtain high transmission efficiency for various WPT scenarios. The aperture size of the proposed shared-aperture dual-band array antenna is reduced by $15 \%$ compared to that when implementing $2.4 \mathrm{GHz}$ and $5.8 \mathrm{GHz}$ arrays individually with equivalent performance and stacking them. WPT experiments according to the operating frequency are conducted in order to validate the developed dual-band RF WPT system. As a result of the WPT experiments when varying the distance and position of the Rx at 2.482 and $5.73 \mathrm{GHz}$, the measured received power was in good agreement with the calculated result. In adddition, transmitting wireless power with the focused beam improves the received power compared to when applying beam-forming. When the distance was varied from $1 \mathrm{~m}$ to $3.92 \mathrm{~m}$ and RF wireless power of $10 \mathrm{~W}$ was transmitted to the Rx by applying the beam-focusing, the received power (WPT efficiencies) at the $2.482 \mathrm{GHz}$ and $5.73 \mathrm{GHz}$ were distributed as $24.75-13.5 \mathrm{dBm}(2.985-0.224 \%)$ and $19.25-6.8 \mathrm{dBm}(0.841-0.050 \%)$, respectively. It was verified that wireless power with frequencies of both 2.482 and $5.73 \mathrm{GHz}$ can be simultaneously transmitted. Furthermore, dual beams of 2.482 and $5.73 \mathrm{GHz}$ can be generated to different receivers separately. Consequently, it is proven that the proposed dual-band RF WPT system is differentiated in 
that it selects the operating frequency on either the 2.4 or $5.8 \mathrm{GHz}$ band and achieves diversity of the operating frequency, unlike the conventional RF WPT system that uses only a single band. Thus, the proposed RF WPT system can be flexibly operated according to the given frequency environment, the WPT scenario, and the operating frequency of the power-receiving device.

For these reasons, it is expected that the dual-band WPT system proposed in this study can be applied to advanced RF WPT technology and can provide convenient wireless charging for various IoT devices, such as sensors, home appliances, medical devices, and robots. Furthermore, the optimizing method of the dual-band array based on the analysis of the received power (or power transmission efficiency) as presented here will be widely applicable in the radar and 5G and 6G communication fields based on array antenna technology.

Author Contributions: Writing, C.-M.S.; array optimization, C.-M.S.; antenna design and simulation, C.-M.S. and S.T.-V.; Implementation system, K.-Y.L., Y.Y. and K.C.H.; Experiment, C.-M.S. and H.-J.L.; Methodology, K.C.H.; Writing Review and Editing, H.-J.L. and K.C.H.; Conceptualization, C.-M.S., S.T.-V., K.-Y.L., Y.Y., and K.C.H. All authors have read and agreed to the published version of the manuscript.

Funding: This work was supported by the National Research Foundation of Korea(NRF) grant funded by the Korea government(MSIT) (2018R1C1B6005024).

Institutional Review Board Statement: Not applicable.

Informed Consent Statement: Not applicable.

Data Availability Statement: The data presented in this study are available on request from the corresponding author.

Conflicts of Interest: The authors declare no conflict of interest.

\section{References}

1. Ciccia, S.; Scionti, A.; Franco, G.; Giordanengo, G.; Terzo, O.; Vecchi, G. A Multi-Tone Rectenna System for Wireless Power Transfer. Energies 2020, 13, 2374. [CrossRef]

2. Choi, K.W.; Ginting, L.; Aziz, A.A.; Setiawan, D.; Park, J.H.; Hwang, S.I.; Kang, D.S.; Chung, M.Y.; Kim, D.I. Toward Realization of Long-Range Wireless-Powered Sensor Networks. IEEE Wireless Commun. 2019, 26, 184-192. [CrossRef]

3. Tran, N.M.; Amri, M.M.; Park, J.H.; Hwang, S.I.; Kim, D.I.; Choi, K.W. A Novel Coding Metasurface for Wireless Power Transfer Applications. Energies 2019, 12, 4488. [CrossRef]

4. Kim, Y.; Boo, S.; Kim, G.; Kim, N.; Lee, B. Wireless Power Transfer Efficiency Formula Applicable in Near and Far Fields. J. Electromagn. Eng. Sci. 2019, 19, 239-244. [CrossRef]

5. Malik, B.T.; Doychinov, V.; Hayajneh, A.M.; Zaidi, S.A.R.; Robertson, I.D.; Somjit, N. Wireless Power Transfer System for Battery-Less Sensor Nodes. IEEE Access 2020, 8, 95878-95887. [CrossRef]

6. Xie, L.; Shi, Y.; Hou, Y.T.; Lou, A. Wireless Power Transfer and Applications to Sensor Networks. IEEE Wirel. Commun. 2013, 20, $140-145$.

7. Yi, X.; Chen, X.; Zhou, L.; Hao, S.; Zhang, B.; Duan, X. A Microwave Power Transmission Experiment Based on the Near-Field Focused Transmitter. IEEE Antennas Wirel. Propag. Lett. 2019, 18, 1105-1108. [CrossRef]

8. Khang, S.-T.; Lee, D.-J.; Hwang, I.-J.; Yeo, T.-D.; Yu, J.-W. Microwave Power Transfer With Optimal Number of Rectenna Arrays for Midrange Applications. IEEE Antennas Wirel. Propag. Lett. 2018, 17, 155-159. [CrossRef]

9. Kang, E.; Hur, J.; Seo, C.; Lee, H.; Choo, H. High Aperture Efficiency Array Antenna for Wireless Power Transfer Applications. Energies 2020, 13, 2241. [CrossRef]

10. Naji, D.K. Miniature Slotted Semi-Circular Dual-Band Antenna for WiMAX and WLAN Applications. J. Electromagn. Eng. Sci. 2020, 20, 115-124. [CrossRef]

11. Sasikala, T.; Arunchandar, R.; Bhagyaveni, M.A.; Shanmuga Priya, M. Design of Dual-Band Antenna for 2.45 and 5.8 GHz ISM Band. Nation Acad. Sci. Lett. 2019, 42, 221-226. [CrossRef]

12. Fereshtian, A.; Ghalibafan, J. Impedance Matching and Efficiency Improvement of a Dual-Band Wireless Power Transfer System Using Variable Inductance and Coupling Method. AEUE Trans. Int. J. Electron. Commun. 2020, 116, 116. [CrossRef]

13. Kung, M.-L.; Lin, K.-H. Dual-Band Coil Module With Repeaters for Diverse Wireless Power Transfer Applications. IEEE Trans. Microw. Theory Techn. 2018, 66, 332-345. [CrossRef]

14. Liu, M.; Chen, M. Dual-Band Wireless Power Transfer With Reactance Steering Network and Reconfigurable Receivers. IEEE Trans. Power Electron. 2020, 35, 496-507. [CrossRef] 
15. Ahn, D.; Mercier, P.P. Wireless Power Transfer With Concurrent 200-kHz and 6.78-MHz Operation in a Single-Transmitter Device. IEEE Trans. Power Electron. 2016, 31, 5018-5029. [CrossRef]

16. Haerinia, M.; Noghanian, S. A Printed Wearable Dual-Band Antenna for Wireless Power Transfer. Sensors 2019, $19,1732$. [CrossRef] [PubMed]

17. Shrestha, S.; Lee, S.R.; Choi, D.Y. A New Fractal-Based Miniaturized Dual Band Patch Antenna for RF Energy Harvesting . Int. J. Antennas Propag. 2014, 2014, 1-9 [CrossRef]

18. Niotaki, K.; Cañavate-Sánchez, M.J.; Collado, A.; Goussetis, G.; Georgiadis, A.; Brazil, T. 2.45/5.8 GHz Dual-Band Power Amplifier for Wireless Power Transfer in Space Applications. In Proceedings of the Active and Passive RF Devices, London, UK, 8 May 2017; pp. 1-4.

19. Bergès, R.; Fadel, L.; Oyhenart, L.; Vigneras, V.; Taris, T. A Dual Band 915MHz/2.44GHz RF Energy Harvester. In Proceedings of the 2015 European Microwave Conference (EuMC), Paris, France, 7-10 September 2015; pp. 307-310.

20. Wang, H.; Deng, L.; Luo, H.; Du, J.; Zhou, D.; Huang, S. Microwave Wireless Power Transfer System Based on a Frequency Reconfigurable Microstrip Patch Antenna Array. Energies 2021, 14, 415. [CrossRef]

21. Miller, T.; Oyewobi, S.S.; Abu-Mahfouz, A.M.; Hancke, G.P. Enabling a Battery-Less Sensor Node Using Dedicated Radio Frequency Energy Harvesting for Complete Off-Grid Applications. Energies 2020, 13, 5402. [CrossRef]

22. Trinh-Van, S.; Lee, J.M.; Yang, Y.; Lee, K.-Y.; Hwang, K.C. Improvement of RF Wireless Power Transmission Using a Circularly Polarized Retrodirective Antenna Array With EBG Structures. Appl. Sci. 2018, 8, 324. [CrossRef]

23. Fairouz, M.; Saed, M.A. A Complete System of Wireless Power Transfer Using a Circularly Polarized Retrodirective Array. J. Electromagn. Eng. Sci. 2020, 20, 139-144 [CrossRef]

24. Kwon, G.; Park, J.Y.; Kim, D.H.; Hwang, K.C. Optimization of a Shared-Aperture Dual-Band Transmitting/Receiving Array Antenna for Radar Applications. IEEE Trans. Antennas Propag. 2017, 65, 7038-7051. [CrossRef]

25. Gal, R.; Shavit, R. Thinning Satellite Communication Antenna Arrays for Dual Band Operation. In Proceedings of the IEEE International Conference on the Science of Electrical Engineering (ICSEE), Eilat, Israel, 12-14 December 2018; pp 1-5.

26. Liu, C; Wu, H.-N. Synthesis of Thinned Array With Side Lobe Levels Reduction Using Improved Binary Invasive Weed Optimization. Prog. Electromagn. Res. M 2014, 37, 21-30. [CrossRef]

27. Brahma, P.; Nandi, P.; Senapati, A.; Roy, J.S. Reduction of Side-Lobe Level of Thinned Phased Array Antenna Using Genetic Algorithm. Int. J. Comput. Appl. 2015, 112, 13-15.

28. Gangwar, V.S.; Samminga, R.K.; Singh, A.K.; Jijenth, M.; Suman, K.K.; Singh, S.P. A Novel Strategy for the Synthesis of Thinned Planar Antenna Array Which Furnishes Lowest Possible Peak Side Lobe Level Without Appearance of Grating Lobes Over Wide Steering Angles. J. Electromagn. Waves Appl. 2018, 32, 842-857. [CrossRef]

29. Razavi, A.; Forooraghi, K. Thinned Arrays Using Pattern Search Algorithms. Prog. Electromagn. Res. 2008, 78, 61-71. [CrossRef]

30. Jain, R.; Mani, G.S. Solving “Antenna Array Thinning Problem” Using Genetic Algorithm. Appl. Comput. Intell. Soft Comput. 2012, 24, 946398. [CrossRef]

31. Balanis, C.A. Antenna Theory: Analysis and Design, 3rd ed.; John Wiley \& Sons: Hoboken, NJ, USA, 2005.

32. Buffi, A.; Nepa, P.; Manara, G. Design Criteria for Near-Field-Focused Planar Arrays. IEEE Antennas Propag. Mag. 2012, 54, 40-50. [CrossRef]

33. Bae, J.; Yi, S.; Koo, H.; Oh, S.; Oh, H.; Choi, W.; Shin, J.; Song, C.M.; Hwang, K.; Lee, K.; et al. LUT-Based Focal Beamforming System Using 2-D Adaptive Sequential Searching Algorithm for Microwave Power Transfer. IEEE Access 2020, 8, 196024-196033. [CrossRef]

34. Li, P.F.; Qu, S.W.; Yang, S.; Nie, Z.P. Microstrip Array Antenna With 2-D Steerable Focus in Near-Field Region. IEEE Trans. Antennas Propag. 2017, 65, 4607-4617. [CrossRef]

35. Song, C.M.; Trinh-Van, S.; Lee, S.-H.; Bae, J.; Yang, Y.; Lee, K.-Y.; Hwang, K.C. Analysis of Received Power in RF Wireless Power Transfer System With Array Antennas. IEEE Access 2021, 9, 76315-76324. [CrossRef]

36. Geary, K.; Schaffner, J.H.; Hsu, H.-P.; Song, H.J.; Colburn, J.S.; Yasan, E. Single-Feed Dual-Band Stacked Patch Antenna for Orthogonal Circularly Polarized GPS and SDARS Applications. In Proceedings of the 2008 IEEE 68th Vehicular Technology Conference, Calgary, AB, Canada, 24 October 2008; pp. 1-5.

37. Wang, X.; Sha, S.; He, J.; Guo, L.; Lu, M. Wireless Power Delivery to Low-Power Mobile Devices Based on Retro-Reflective Beamforming. IEEE Antennas Propag. Mag. 2014, 13, 919-922. [CrossRef]

38. Gowda, V.R.; Yurduseven, O.; Lipworth, G.; Zupan, T.; Reynolds, M.S.; Smith, D.R. Wireless Power Transfer in the Radiative Near Field. IEEE Antennas Wirel. Propag. Lett. 2016, 15, 1865-1868. [CrossRef] 